\title{
On the Accuracy of Wind Measurements Using an Inertial Platform in an Aircraft, and an Example of a Measurement of the Vertical Mesostructure of the Atmosphere ${ }^{1}$
}

\author{
D. N. AXForD \\ Meteorological Research Flight, Farnborough, England \\ (Manuscript received 8 December 1967, in revised form 25 March 1968)
}

\begin{abstract}
A high quality inertial navigation platform, originally developed for the TSR 2 aircraft, is now being used by the Meteorological Research Flight in order to measure vertical gust velocities and horizontal wind shear from a Canberra PR 3 aircraft.

The equations are derived from which the vertical and horizontal winds are calculated, and an assessment is made of the accuracy of measurement which can be expected for vertical gusts and horizontal shear. Measurements of the residual error velocities which occur when the aircraft is made to pitch, roll and yaw are shown to lie within the theoretical limits, and an example of the velocities derived from a straight and level run in smooth air is also described.

The use of this equipment to measure the small-scale variations in wind shear and vertical gusting when the aircraft descends through a layer of turbulence is then described, and the results of one of the first of a series of such flights are given. With the present recording system, the extraction of data for the analysis of a few minutes of flight is lengthy, but it is hoped that a data recording system will be installed in the future. The system will then become a quick and accurate method of measuring the mesoscale structure of the gusts and shears in the atmosphere.
\end{abstract}

\section{Introduction}

Vertical and horizontal air movements in the atmosphere are of importance at all scales from the small motions in turbulent diffusion to the long global wavelengths which occur in the upper troposphere. An aircraft is a tool which is suitable for investigating fluctuations on a scale from $10-10^{5} \mathrm{~m}$, i.e., the mesostructure of the atmosphere. An aircraft can move rapidly to a suitable point within the atmosphere, and make horizontal and vertical soundings during periods from 5 min to $3-4 \mathrm{hr}$.

Measurements of up- and downdrafts in cumulus, horizontal and vertical gusts in clear air turbulence, the oscillatory motions in lee waves, and the detailed structure of the atmosphere in the neighborhood of a jet stream are all within the province of aircraft measurement, and have been the subject of much research in the last few years.

One of the major problems in making measurements from a flying laboratory is to specify adequately the motion and attitude of the aircraft. Until recently, in the Meteorological Research Flight, gusts experienced have been estimated from the acceleration of the aircraft taking into account the dimensions, weight and lift characteristics. The addition of wind vanes on a nose probe to define the angles of attack and sideslip

\footnotetext{
${ }^{1}$ Copyright, Controller, Her Majesty's Stationery Office.
}

of the air relative to the aircraft, and the addition of stabilized accelerometers has followed as a logical development. Telford and Warner (1962) describe how this is done for the vertical gust component in a similarly instrumented aircraft. However, the normal aircraft gyroscopes used have not had sufficient stability for more than 20-30 sec of flight time (Watson, 1967).

A high quality inertial navigation platform (FSP 100), originally developed for the TSR 2 aircraft, is now being used by the Meteorological Research Flight. This platform was developed by Ferranti, Ltd., and the Inertial Navigation Division of the Instruments and Electrical Engineering Dept., Royal Aircraft Establishment, Farnborough. It forms the basic stable reference frame within which measurements of vertical and horizontal gusts and wind shear may be obtained, and its stability is sufficient for periods of $5-10 \mathrm{~min}$ of flight time. The use of the inertial platform for this work has recently been described by Ross (1966) who summarizes the principles of the inertial equipment, and gives an example of its use in measuring vertical gusts. The purpose of the present paper is to demonstrate the necessity for taking second-order terms in the gust equations into account when using this equipment, to assess the accuracy of the measurements, and to give an interesting example of its use in measuring the mesoscale variations in wind shear in the vertical. 


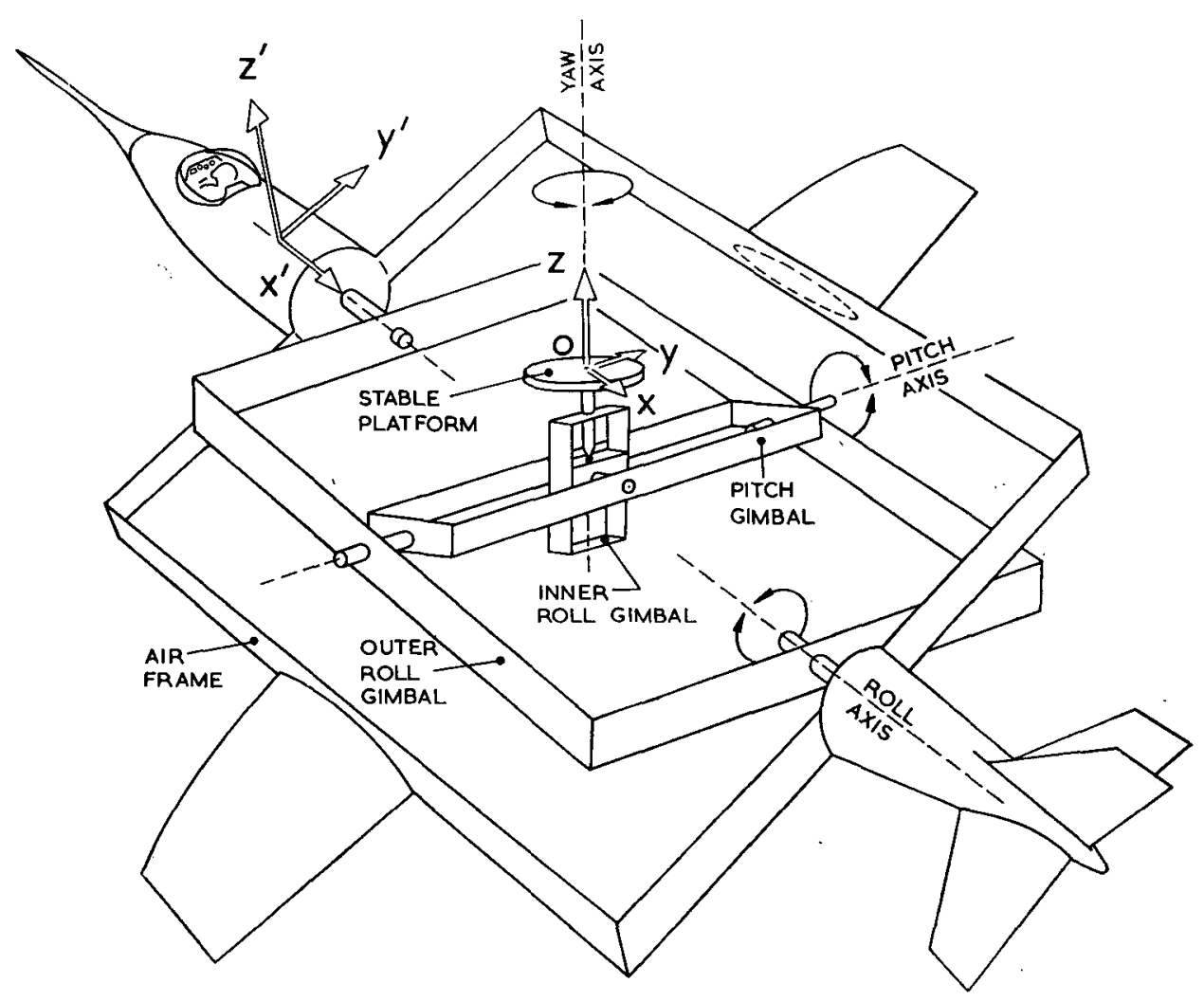

FIg. 1. Platform gimbals and reference frames. The aircraft reference axes $O x^{\prime}, O y^{\prime}, O z^{\prime}$ are shown on the aircraft for clarity. Their true origin is at the platform reference axes origin $O$.

The inertial platform is mounted in the flare bay of the Canberra aircraft beneath, and to the rear of, the wings. The nose probe carrying the two wind vanes is $12 \mathrm{ft}$ long, and is horizontal in normal flight. The wind vanes are of light alloy, with a natural period of less than $0.1 \mathrm{sec}$, and record the angles of attack and sideslip. The platform provides a complete record of attitude angles, accelerations and velocities of the aircraft.

\section{Derivation of the gust equations}

Measurements are made of the following parameters:

1) $U$, the air velocity relative to the aircraft and along its $x^{\prime}$-axis.

2) $\alpha$, the angle of attack, the angle in the $x^{\prime}-z^{\prime}$ plane between the $x^{\prime}$-axis and the airstream.

3 ) $\beta$, the angle of sideslip, the angle in the $x^{\prime}-y^{\prime}$ plane between the $x^{\prime}$-axis and the airstream.

4) Pitch angle $\theta$, roll angle $r$, and yaw angle $\phi$, in which $\theta, r$ and $\phi$ are defined below to be those angles measured by the Ferranti inertial stable platform (FSP 100).

5) $V_{x}, V_{y}, V_{z}$, the components of the aircraft velocity with respect to the platform frame of reference.
These are derived from an electromechanical integration of the accelerations measured within the inertial platform. The z-axis is maintained in the local vertical.

To derive the wind components of the airflow relative to a fixed set of axes in space, it is necessary to transfer from the moving reference frame in the aircraft to the platform frame. The center of the Ferranti inertial platform is taken to be the origin of reference $O$.

Take platform reference frame axes $O x, O y, O z$, such that $O x$ points backward along the initial horizontal path of the aircraft, $O z$ vertically upwards, and $O y$, completing the right-handed system, to starboard. These axes are shown on the reference platform in Fig. 1.

Let $O x^{\prime}, O y^{\prime}, O z^{\prime}$ be the instantaneous axes of the aircraft after it has yawed $\phi^{\prime}$, pitched $\theta^{\prime}$, and rolled $r^{\prime}$ in the gimbal system shown.

Now, suppose $V_{\text {aircraft }}$ is a vector in the aircraft frame of reference. Then, in order to represent this vector in the platform frame of reference, it is necessary to make a series of rotations, i.e.,

$$
\left.\begin{array}{ll}
\mathbf{V}_{\text {outer roll gimbal }} & =A_{1}\left(r^{\prime}\right) \mathbf{V}_{\text {aircrait }} \\
\mathbf{V}_{\text {pitch gimbal }} & =A_{2}\left(\theta^{\prime}\right) A_{1}\left(r^{\prime}\right) \mathbf{V}_{\text {aircraft }} \\
\mathbf{V}_{\text {platform }} & =A_{3}\left(\phi^{\prime}\right) A_{2}\left(\theta^{\prime}\right) A_{1}\left(r^{\prime}\right) \mathbf{V}_{\text {aircraft }}
\end{array}\right\},
$$


where

$$
\begin{aligned}
& A_{1}\left(r^{\prime}\right)=\left[\begin{array}{ccc}
1 & 0 & 0 \\
0 & \cos r^{\prime} & \sin r^{\prime} \\
0 & -\sin r^{\prime} & \cos r^{\prime}
\end{array}\right] \\
& A_{2}\left(\theta^{\prime}\right)=\left[\begin{array}{ccc}
\cos \theta^{\prime} & 0 & -\sin \theta^{\prime} \\
0 & 1 & 0 \\
\sin \theta^{\prime} & 0 & \cos \theta^{\prime}
\end{array}\right] \\
& A_{3}\left(\phi^{\prime}\right)=\left[\begin{array}{ccc}
\cos \phi^{\prime} & \sin \phi^{\prime} & 0 \\
-\sin \phi^{\prime} & \cos \phi^{\prime} & 0 \\
0 & 0 & 1
\end{array}\right]
\end{aligned}
$$

are the transformation matrices representing righthanded rotations about positive coordinate axes. [See, for example, Broxmeyer (1964)].

It is conventional to measure roll by the left wing-up angle $r$, pitch by the nose-up angle $\theta$, and yaw by the left wing forward angle $\phi$. Thus, the rotations required are those defined by

$$
r^{\prime}=r, \quad \theta^{\prime}=-\theta, \quad \phi^{\prime}=\phi .
$$

Thus, from Eq. (1)

$$
\mathrm{V}_{\text {platform }}=T \mathrm{~V}_{\text {aircraft }}
$$

where

$$
T=A_{3}(\phi) A_{2}(-\theta) A_{1}(r) .
$$

Therefore, multiplying out the above expression, we have

$$
T=\left[\begin{array}{ccc}
\cos \theta \cos \phi & \sin \phi \cos r-\sin \theta \cos \phi \sin r & \sin \phi \sin r+\sin \theta \cos \phi \cos r \\
-\cos \theta \sin \phi & \cos \phi \cos r+\sin \theta \sin \phi \sin r & \cos \phi \sin r-\sin \theta \sin \phi \cos r \\
-\sin \theta & -\cos \theta \sin r & \cos \theta \cos r
\end{array}\right]
$$

Now let $(u, v, w)$ be the values of the gust components of the external wind field, and let $\left(V_{x}, V_{y}, V_{z}\right)$ be the components of the aircraft motion or translation with respect to the platform frame of reference.

Measurements of $U, \alpha$ and $\beta$ give gust components in the aircraft frame of reference of $U$ along the $x^{\prime}$ axis, $U \tan \beta$ along the $y^{\prime}$-axis, and $U \tan \alpha$ along the $z^{\prime}$-axis. Transforming to the platform frame of reference, we then have

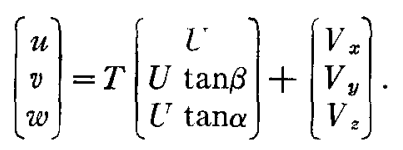

It is clear that if a measuring instrument, such as a wind vane, is not at the origin $O$, further terms will arise in Eq. (3) due to the rate of pitch $\dot{\theta}$, roll $\dot{r}$ and yaw $\dot{\phi}$.

Let the instrument be at the fixed point $\mathbf{p}^{\prime}(l, m, n)$ in the aircraft frame of reference. Then the velocities due to the rate of rotation will have the same effect as a translation, and must be added to the right-hand side of Eq. (3) after transformation to the platform reference frame.

The space velocity of a point $\mathbf{r}(x, y, z)$ which is fixed relative to a rotating frame of reference is given by $\boldsymbol{\Omega} \wedge \mathbf{r}$ where $\boldsymbol{\Omega}$ is the angular velocity vector $\left(\Omega_{x}, \Omega_{y}, \Omega_{z}\right)$. In our case the point $\mathbf{p}^{\prime}(l, m, n)$ can be transformed readily from the aircraft frame of reference to the platform frame by the transformation

$$
\mathbf{p}_{\text {platform }}=T \mathbf{p}_{\text {aircraft }}^{\prime}
$$

The angular velocity in the platform frame consists of three parts:
$\boldsymbol{\Omega}_{1}=(0,0,-\phi)$, due to rate $-\dot{\phi}$ of yaw,

$$
\begin{aligned}
\boldsymbol{\Omega}_{2} & =A_{3}(\phi)\left[\begin{array}{l}
0 \\
\dot{\theta} \\
0
\end{array}\right] \\
& =[\dot{\theta} \sin \phi, \dot{\theta} \cos \phi, 0], \text { due to rate of pitch } \dot{\theta} \text {, and }
\end{aligned}
$$

$$
\mathbf{\Omega}_{3}=A_{3}(\phi) A_{2}(-\theta)\left(\begin{array}{c}
-\dot{r} \\
0 \\
0
\end{array}\right]
$$

$=[-\dot{r} \cos \theta \cos \phi, \dot{r} \cos \theta \sin \phi, \dot{r} \sin \theta]$, due to a rate of roll $-\dot{r}$.

Thus, $\boldsymbol{\Omega}_{\text {platform }}=\boldsymbol{\Omega}_{\mathbf{1}}+\boldsymbol{\Omega}_{\mathbf{2}}+\boldsymbol{\Omega}_{\mathbf{3}}$, and the rotational velocities in the platform frame of reference are given by

$$
\boldsymbol{\Omega}_{\text {platform }} \wedge\left(T \mathbf{p}^{\prime}\right) .
$$

In practice, the vanes are a distance $L$ to the front of the aircraft, so that $l=-L$, and $L \gg m, n$ in the Canberra. With $\theta, \phi$ and $r$ all relatively small, many terms in $m$ and $n$ may be dropped, and approximate solutions for the rotational terms are as follows:

$$
\Omega \wedge\left(T \mathbf{p}^{\prime}\right)=\left(\begin{array}{r}
L \cos \theta \sin \phi \dot{\phi}+L \sin \theta \cos \phi \dot{\theta} \\
+[m, n \text { terms }] \\
L \cos \theta \cos \phi \dot{\phi}-L \sin \theta \sin \phi \dot{\theta} \\
+n \cos \phi \cos r \dot{r}+n \cos \theta \cos r \sin \phi \dot{\theta} \\
+[m, n \text { terms }] \\
L \cos \theta \dot{\theta}-m \cos \theta \cos r \dot{r}-n \cos \theta \sin r \dot{r} \\
+[m, n \text { terms }]
\end{array}\right]
$$

Thus, Eq. (3) becomes

$$
\left[\begin{array}{c}
u \\
v \\
w
\end{array}\right]=T\left[\begin{array}{c}
U \\
U \\
\tan \beta \\
U \tan \alpha
\end{array}\right]+\left(\begin{array}{c}
V_{x} \\
V_{y} \\
V_{z}
\end{array}\right)+\boldsymbol{\Omega} \wedge\left(T \mathbf{p}^{\prime}\right)
$$


which may be expanded to give

$$
\begin{aligned}
u= & U \cos \theta \cos \phi+U \tan \alpha(\sin \phi \sin r+\sin \theta \cos \phi \cos r) \\
& +U \tan \beta(\sin \phi \cos r-\sin \theta \cos \phi \sin r) \\
& +V_{x}+L \cos \theta \sin \phi \dot{\phi}+L \sin \theta \cos \phi \dot{\theta} \\
& +[m, n \text { terms }], \\
v= & -U \cos \theta \sin \phi+U \tan \alpha(\cos \phi \sin r-\sin \theta \sin \phi \cos r) \\
& +U \tan \beta(\cos \phi \cos r+\sin \theta \sin \phi \sin r) \\
& +V_{y}+L \cos \theta \cos \phi \phi+n \cos \phi \cos r \dot{r} \\
& +n \cos \theta \cos r \sin \phi \dot{\theta}-L \sin \theta \sin \phi \dot{\theta} \\
& \quad+[m, n \text { terms }], \\
w= & -U \sin \theta+U \tan \alpha \cos \theta \cos r-U \tan \beta \cos \theta \sin r \\
& +L \cos \theta \dot{\theta}+V_{z}-\cos \theta \dot{r}(m \cos r+n \sin r) \\
& \quad+[m, n \text { terms }] .
\end{aligned}
$$

The full equation containing all $m$ and $n$ terms can be calculated readily from Eq. (7) if required.

It should be noted that in using Eqs. (8) it is not necessary to restrict the flight pattern in any way with reference to aircraft trim settings or accelerations. At any time $t$ after the initial start point, the inertial platform specifies the change in aircraft velocity, and the aircraft attitude with regard to space axes. Thus, if the initial aircraft velocity in space is known, for example by Doppler radar and static pressure measurements, the motion at time $t$ can be deduced, and from these measurements and the true airspeed $U(t)$ the wind components are specified precisely.

\section{Theoretical estimation of the accuracy of calcu- lated gusts}

It is first necessary to estimate the orders of magnitude, and the degree of accuracy of the variables used in Eqs. (8). These are shown in Table 1, where average values are used for the order-of-magnitude term.

The basic accuracy of $r, \theta$ and $\phi$ claimed by the manufacturer is $1.5 \mathrm{~min}$ of arc, but this has been lowered in all cases because of the method of recording

TABLE 1. Gust equation parameters.

\begin{tabular}{ccc}
\hline \hline Parameter & $\begin{array}{c}\text { Order of } \\
\text { magnitude }\end{array}$ & $\begin{array}{c}\text { Estimate of } \\
\text { accuracy }(\Delta)\end{array}$ \\
\hline$U$ & $210 \mathrm{~m} \mathrm{sec}-1$ & $1 \% 2.1 \mathrm{~m} \mathrm{sec}^{-1}$ \\
$\alpha$ & $0.03 \mathrm{rad}$ & $2 \% 0.0006 \mathrm{rad}$ \\
$\beta$ & $0.03 \mathrm{rad}$ & $2 \% 0.0006 \mathrm{rad}$ \\
$r$ & $0.12 \mathrm{rad}$ & $2 \% 0.0024 \mathrm{rad}$ \\
$\theta$ & $0.06 \mathrm{rad}$ & $2 \% 0.0012 \mathrm{rad}$ \\
$\phi$ & $0.06 \mathrm{rad}^{-1}$ & $2 \% 0.0012 \mathrm{rad}$ \\
$\dot{r}, \dot{\theta}, \phi$ & $0.02 \mathrm{rad} \mathrm{sec}$ & $2 \% 0.0004 \mathrm{rad} \mathrm{sec}^{-1}$ \\
$V_{x}, V_{y}, V_{z}$ & $7 \mathrm{~m} \mathrm{sec}$ & $2 \% 0.14 \mathrm{mec}^{-1}$ \\
$L$ & $12 \mathrm{~m}$ & $2 \%$ \\
$m, n$ & $0.15 \mathrm{~m}$ & $2 \%$ \\
$L \dot{\theta}, L \dot{\phi}$ & $0.25 \mathrm{~m} \mathrm{sec}$ & $2 \%$ \\
$m \dot{r}, n \dot{r}, m \dot{\phi}\}$ & $0.0005 \mathrm{~m} \mathrm{sec}^{-1}$ & $2 \%$ \\
$n \dot{\phi}, m \dot{\theta}, n \dot{\theta}\}$ & & \\
\hline
\end{tabular}

via a galvanometer onto a photographic trace. This method introduces inaccuracies due to errors or changes in the calibration, and to nonlinear sensitivities. The maximum accuracy that can be achieved at present for these parameters has been taken to be $2 \%$.

The measurement of $U$, the aircraft velocity, is made in the conventional manner from the pitot-static system in the nose probe. Since the static vents are affected by lateral turbulent gusts, and airspeed changes occur in turbulence of up to $1.5 \mathrm{~m} \mathrm{sec}^{-1}$ in short time periods, it is not practicable to make this measurement to an accuracy better than $1 \%$. Thus, in most straight and level experimental runs a mean value of $U$ is taken for each run. However, during any period of flight $>\sim 30 \mathrm{sec}$, changes of 2-4\% may occur in $U$. In this case the flight analysis has to be divided into suitable sections, in which $U$ is kept constant, or, alternatively, $U$ may be made into a further variable parameter.

a. Verical gusts w. Let us consider now the significant magnitudes of the terms in Eq. (8c). It is apparent that the important terms are

$$
\begin{aligned}
& w=-U \sin \theta \quad \sim 12 \mathrm{~m} \mathrm{sec}^{-1} \\
& +U \tan \alpha \cos \theta \cos r \sim 7 \mathrm{~m} \mathrm{sec}^{-1} \\
& -U \tan \beta \cos \theta \sin r \quad \sim 0.7 \mathrm{~m} \mathrm{sec}^{-1} \\
& +V_{z} \quad \sim 7 \mathrm{~m} \mathrm{sec}^{-1} \\
& + \text { terms of magnitude }<0.3 \mathrm{~m} \mathrm{sec}^{-1} \text {. }
\end{aligned}
$$

Then, errors due to inaccuracies of $1 \%$ in $U$, and $2 \%$ in $\alpha, \beta, \theta, r$ and $V_{z}$ will give a total error, neglecting $(9 c)$ and using Table 1 , of

$$
\begin{aligned}
\Delta(U \sin \theta) & +\Delta(U \tan \alpha \cos \theta \cos r)+\Delta\left(V_{z}\right) \\
\simeq 0.06 \times 2.1 & +210 \times 0.0012+0.03 \times 2.1 \\
& +210 \times 0.0006+0.14 \simeq 0.8 \mathrm{~m} \mathrm{sec}^{-1} .
\end{aligned}
$$

Thus, a maximum error of about $1 \mathrm{~m} \mathrm{sec}^{-1}$ is inherent in vertical gust measurements.

b. Lateral gusts $v$. In this case Eq. (8b) is used and we have

$$
\begin{aligned}
& v=-U \cos \theta \sin \phi \quad \sim 12 \mathrm{~m} \mathrm{sec}^{-1} \\
& +U \tan \alpha \cos \phi \sin r \sim 0.7 \mathrm{~m} \mathrm{sec}^{-1} \\
& +U \tan \beta \cos \phi \cos r \sim 7 \mathrm{~m} \mathrm{sec}^{-1} \\
& +V_{y} \sim 7 \mathrm{~m} \mathrm{sec}^{-1} \\
& + \text { terms of magnitude }<0.3 \mathrm{~m} \mathrm{sec}^{-1} \text {. }
\end{aligned}
$$

Neglecting (10b), the total error of

$$
\begin{array}{r}
\Delta(U \cos \theta \sin \phi)+\Delta(U \tan \beta \cos \phi \cos r)+\Delta\left(V_{y}\right) \\
\simeq 0.06 \times 2.1+210 \times 0.0012+0.03 \times 2.1+210 \\
\times 0.0006+0.14 \simeq 0.8 \mathrm{~m} \mathrm{sec}^{-1} .
\end{array}
$$

Thus, the errors inherent in the lateral wind measure- 
ment are of the same order of magnitude as those for vertical gusts, a maximum of about $1 \mathrm{~m} \mathrm{sec}^{-1}$.

c. Longitudinal gusts $u$. Eq. (8a) gives

$$
\begin{aligned}
& u=U \cos \theta \cos \phi \quad 210 \quad \mathrm{~m} \mathrm{sec}^{-1} \\
& +U \tan \alpha \sin \theta \cos \phi \cos r \sim 0.75 \mathrm{~m} \mathrm{sec}^{-1} \\
& +U \tan \beta \sin \phi \cos r \sim 0.75 \mathrm{~m} \mathrm{sec}^{-1} \\
& +V_{z} \sim 7 \mathrm{~m} \mathrm{sec}^{-1} \\
& + \text { terms of magnitude }<0.3 \mathrm{~m} \mathrm{sec}^{-1} \text {. }
\end{aligned}
$$

Neglecting (11b) and (11c), the total error in this case of $\Delta(U \cos \theta \cos \phi)+\Delta\left(V_{x}\right) \simeq 2.1+0.14 \simeq 2.2 \mathrm{~m} \mathrm{sec}^{-1}$.

In order to measure the longitudinal wind changes, the initial value of the true airspeed $U_{0}$ is subtracted from the value given above. It is clear that longitudinal gusts can only be measured to an accuracy of $1 \mathrm{~m} \mathrm{sec}^{-1}$ if the accuracy of measurement of the airspeed $U$ $>0.5 \%$. At present, it is not possible to differentiate between true changes in airspeed and the static error terms introduced by gustiness, or periods of sideslip or pitching in the aircraft flight pattern. Thus, at present, accurate longitudinal measurements of gusts are impractical, and longer term longitudinal wind measurement has a limited accuracy of $2-2.5 \mathrm{~m} \mathrm{sec}^{-1}$. However, if flight conditions are such that static error is unlikely to be changed during the period of interest, such as in straight and level flight in smooth air, then the subtraction of $U_{0}$ to obtain the change in $u$ removes most of the initial error, and an accuracy of $\pm 1 \mathrm{~m} \mathrm{sec}^{-1}$ may be practicable for a limited period.

d. Extreme conditions of flight. The assessment of accuracies calculated above covers average flight conditions. However, in extreme conditions such as those found in severe clear air turbulence or in cumulonimbus, it is probable that the accuracy of readings from the photographic trace will deteriorate, since the parameters are changing very quickly. Furthermore, the second-order terms in Eqs. (9c), (10b), (11b) and (11c) and the rate-of-change terms all become important, with values up to $3 \mathrm{~m} \mathrm{sec}^{-1}$. The deterioration in accuracy in these cases is difficult to assess, but a factor of order 1.5 might be applicable.

Thus, in most conditions found in flight, measurements of vertical gusts and lateral wind changes are made within an accuracy of $\pm 1 \mathrm{~m} \mathrm{sec}^{-1}$, but in cases of severe disturbance, accuracy may deteriorate to $\pm 1.5 \mathrm{~m} \mathrm{sec}^{-1}$. These measurements are, of course, with respect to the initial velocity of the platform reference frame.

e. Gyroscope drift in the inertial platform. The inertial platform provides data on the inertial velocities of the aircraft in three coordinate axes, two horizontal directions stabilized in direction, and the local vertical. All inertial platforms depending on gyroscopes for their stability tend to drift slowly from the initial position owing to friction in the gyroscope bearings and slight imbalances in construction. The FSP 100 stable platform has a drift rate of the order of $1 \mathrm{~m} \mathrm{sec}^{-1} \mathrm{~min}^{-1}$ for each of the velocity components. The vertical integrator is not permitted to run for longer than $10 \mathrm{~min}$, since the increasing drift error gives incorrect vertical velocities which will eventually saturate the electromechanical integrator. At the end of $10 \mathrm{~min}$, therefore, the vertical integrator is run back to zero, from which point a further test run may be made.

It is possible to correct for the drift error over short intervals of time up to 5 or even $10 \mathrm{~min}$, since it varies almost linearly over a short time interval.

The drift errors in the horizontal velocities are constrained to vary systematically along sine waves of periods greater than an hour, since the platform is Schuler tuned. Again the drift error over periods of 5-10 min is "almost" linear, so a best fit straight line gives a reasonable estimate of the drift. In the case of the horizontal velocities, flights made in reciprocal directions in a period which is short, so that the drift rate remains the same, will show up the drift error as a common signal, which may then be eliminated.

This long-term drift adds a further element of error to the results, which will be small over periods $\leqslant 1 \mathrm{~min}$, but will increase as the length of flight which is of interest increases. A method of reducing the overall drift of the system is to use the long-term stability of a Doppler navigational instrument as a continuous check on the platform horizontal velocities (Dopplermixing), and the long-term stability of the static pressure height as a continuous check on the vertical velocities. A system such as this can reduce the gyroscope drifts by an order of magnitude, and also allows the continuous use of the platform throughout a flight.

\section{Examples of pilot-induced pitch, roll and yaw}

In order to test the accuracy of the system, the M. R. F. Canberra was flown in clear, smooth air, and the pilot was asked to move his controls to produce pitching, rolling and yawing motions. Five of these tests are described: long- and short-period pitching motions, a short-period roll, and long- and short-period yawing motions.

The aim was to produce motions in which the separate components in Eqs. (8) are large, i.e., equivalent to severe turbulence. If the equations, sensitivities and measurements are accurate, the derived gust velocities, which should be nil in smooth air, will be reduced to a size within the limits of accuracy described in Section 3 , and these residuals can be described as the noise level of the system.

a. Long-period pitching test. Fig. 2a shows the recorder traces from which the basic data for the test are derived. The vertical velocity outputs are in the form of digital pulses, a change of $0.12 \mathrm{~m} \mathrm{sec}^{-1}$ being indicated by each change in the pulse level. For the 


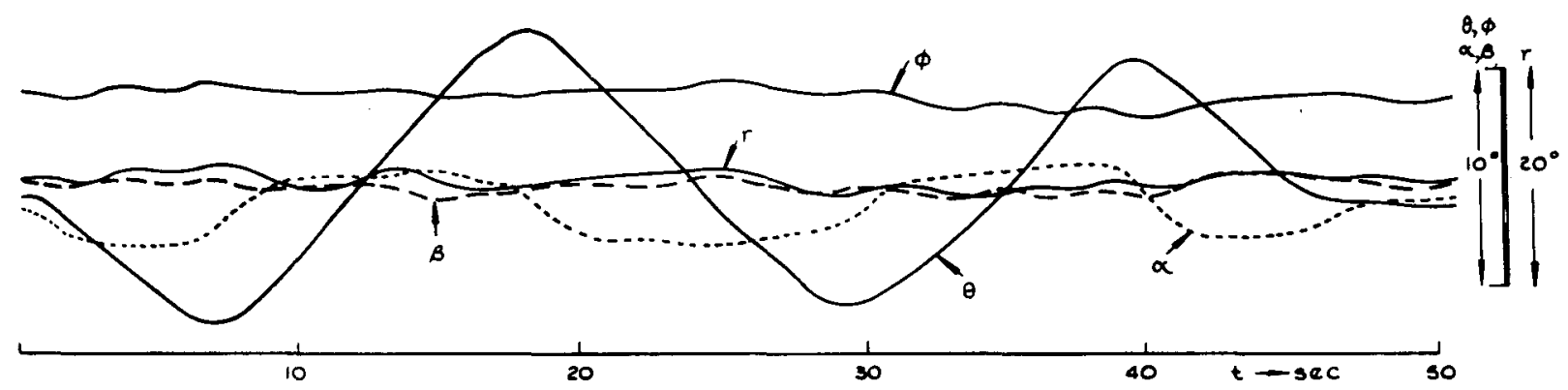

Fig. 2a. Recorder traces for long-period pitching test.

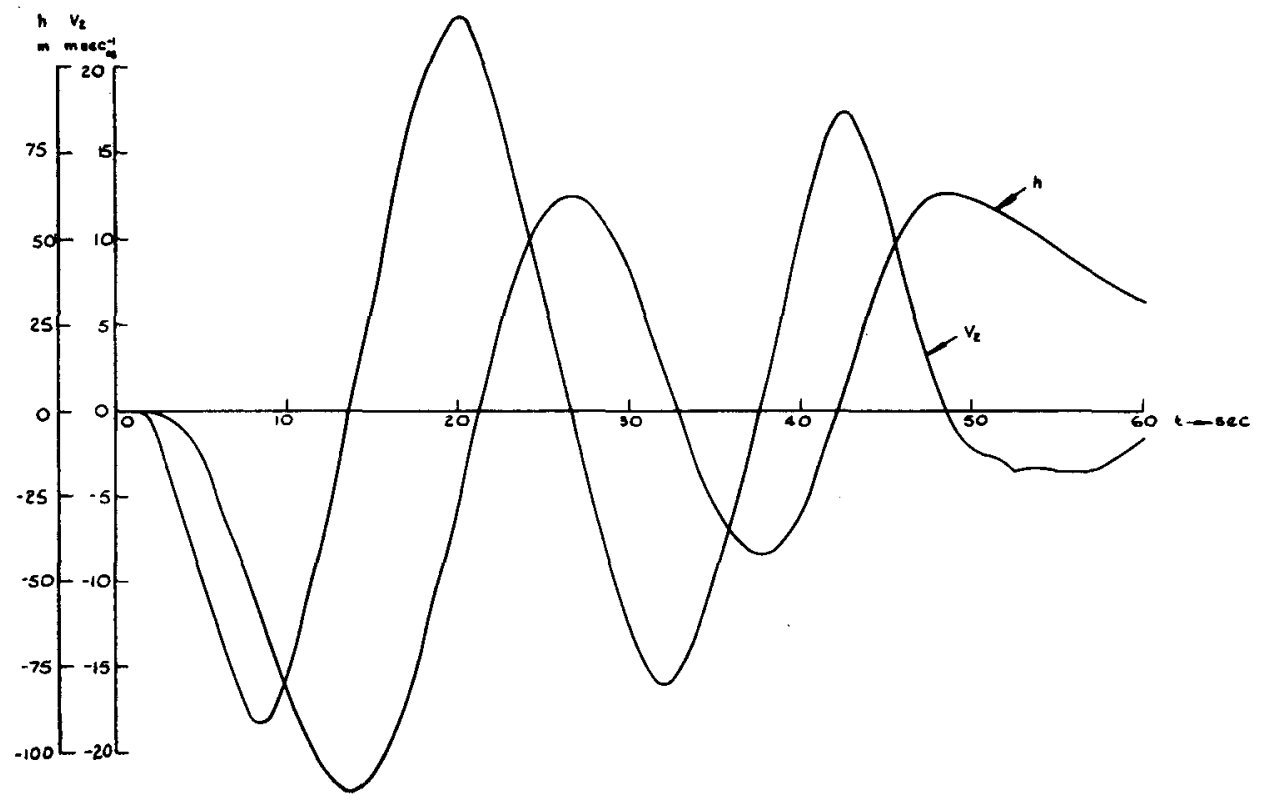

FIG. 2b. Vertical velocity $V_{z}$ and change of height $h$ during long-period pitching test.

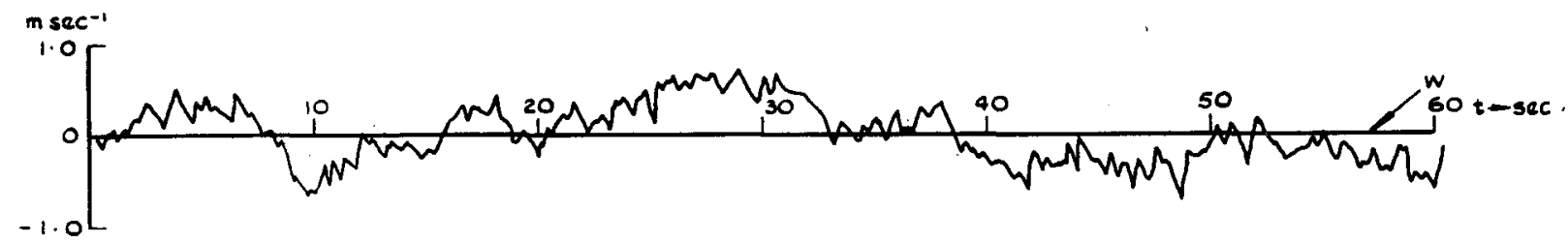

Fig. 2c. Derived vertical gusts $w$ during long-period pitching test.

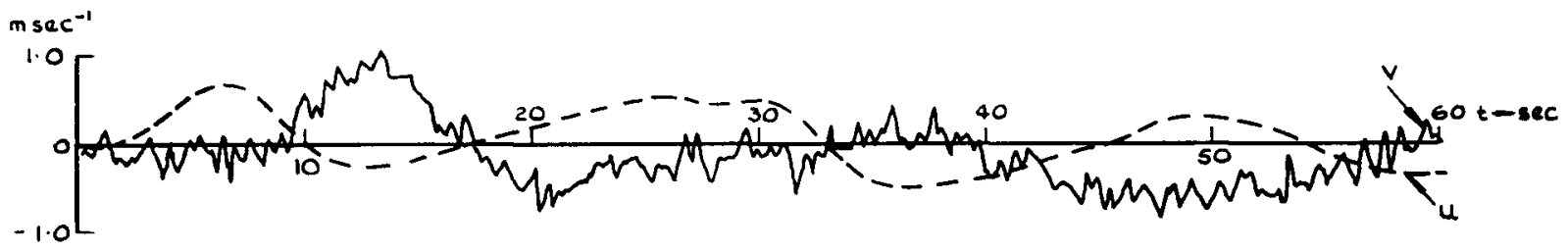

Fig. 2d. Derived lateral gust $v$ and longitudinal gust $u$ during long-period pitching test.

sake of clarity, these and various other parameters measured in flight (temperature, lapsed time, etc.) have been removed, leaving the five attitude traces.

In this record the pitch angle $\theta$ is varying between $\pm 7^{\circ}$ with a period of about $24 \mathrm{sec}$. Fig. $2 \mathrm{~b}$ shows the changes in vertical velocity of the aircraft, and the changes in height deduced from the inertial platform. Figs. $2 \mathrm{c}$ and $2 \mathrm{~d}$ show the vertical, lateral and horizontal velocities derived from Eqs. (8), using a time interval of $0.25 \mathrm{sec}$ between each point. It is evident that the vertical motion has been removed, and that there is a noise level of about $\pm 0.7 \mathrm{~m} \mathrm{sec}^{-1}$. 
During this motion there were considerable changes in the aircraft forward velocity. In order to remove these from the longitudinal gust $u$, measured values of airspeed $U$ are required at each point. Unfortunately, the current pitot-static system gives large static errors with changes in angle of attack, so the true value of $U$ is not known to great accuracy, and the deduced value of longitudinal velocity $u$ is only a smoothed value. However, the calculated values shown in Fig. $2 \mathrm{~d}$ are within $\pm 1 \mathrm{~m} \mathrm{sec}^{-1}$ in this case.

The measurement of airspeed $U$ is to be improved by the use of a compensated pitot-static tube which is less sensitive to variations of pitch and yaw in the near future.

b. Short-period pitching test. Fig. 3a shows the recorder trace for this motion. A series of pitches of $\pm 5^{\circ}$ with a period of about $3 \frac{1}{2} \mathrm{sec}$ was induced, with little or no change in heading or roll angles. In this case the large terms in Eqs. (8), such as $-U \sin \theta$, are ranging from +20 to $-20 \mathrm{~m} \mathrm{sec}^{-1}$, and it is found that the differential term $L \dot{\theta}$ is becoming important.

The residual vertical gust velocities are shown in Fig. 3b. Here it is clear that a disturbance has occurred, but the velocities have been reduced to less than \pm 1 $\mathrm{m} \mathrm{sec}^{-1}$.

c. Short-period rolling test. Eqs. (8) imply that rolling is not of vital importance in measurements of $w$ and $v$, but the rolling term does occur as a second-order effect. Fig. 4a shows a series of rolls of $\pm 12^{\circ}$ with a period close to $4 \mathrm{sec}$. The rolls induced a sympathetic set of minor yaws, which are shown to be mainly sideslip by the fact that the yawing vane $\beta$ reacts in phase with the azimuth $\phi$. Figs. $4 \mathrm{~b}$ and $4 \mathrm{c}$ show the calculated values of vertical gust $w$ and horizontal lateral gust $v$.

In this case, not only was the differential term $L \dot{\phi}$ of importance, with maximum values of $\pm 1.5 \mathrm{~m} \mathrm{sec}^{-1}$, but also the second-order terms $U \tan \alpha \sin r \cos \phi$ and
$-U \tan \beta \sin r \cos \theta$ became significant with values up to $\pm 1.2 \mathrm{~m} \mathrm{sec}^{-1}$. It should be noticed that, because these are nonlinear terms, absolute zero values for the wind vane traces must be used in the gust calculations, and not just the value of the change in vane position from an arbitrary starting point.

d. Short-period yawing test. This yawing motion, shown in Fig. 5a, consists of a series of yaws of extent $\pm 8^{\circ}$ and period about $4 \mathrm{sec}$. The record shows that this motion gave rise to complementary rolls and a variation in the pitch angle. The static errors in the height $h$ and airspeed $q$ due to the yawing motion are large in this case. The major velocity terms in Eqs. (8) due to the large changes in azimuth are of order of magnitude $\pm 20 \mathrm{~m} \mathrm{sec}^{-1}$, and both second-order and differential terms are of considerable importance, maximum values reaching $\pm 3 \mathrm{~m} \mathrm{sec}^{-1}$.

Fig. 5b shows the vertical gust $w$ calculated from this record, and, although there is a recognizable disturbance, it lies within $\pm 1 \mathrm{~m} \mathrm{sec}^{-1}$.

The horizontal lateral gust $v$ shown in Fig. 5c has a considerable residual velocity disturbance of $\pm 1.5 \mathrm{~m}$ $\mathrm{sec}^{-1}$ maximum. This residual may be attributed to the following factors:

1. Lack of linearity in the system, and errors of calibration.

2. Errors in taking measurements from the record. In a case where $\phi$ is changing very rapidly with time, small errors become far more important than usual.

3. When the aircraft is sideslipping through the air, as occurs in this maneuver, it is possible that the deflection and disturbance of the airstream will extend along the aircraft nose probe as far as the yaw vane. Thus, some of the residual error may be due to the presence of the aircraft.

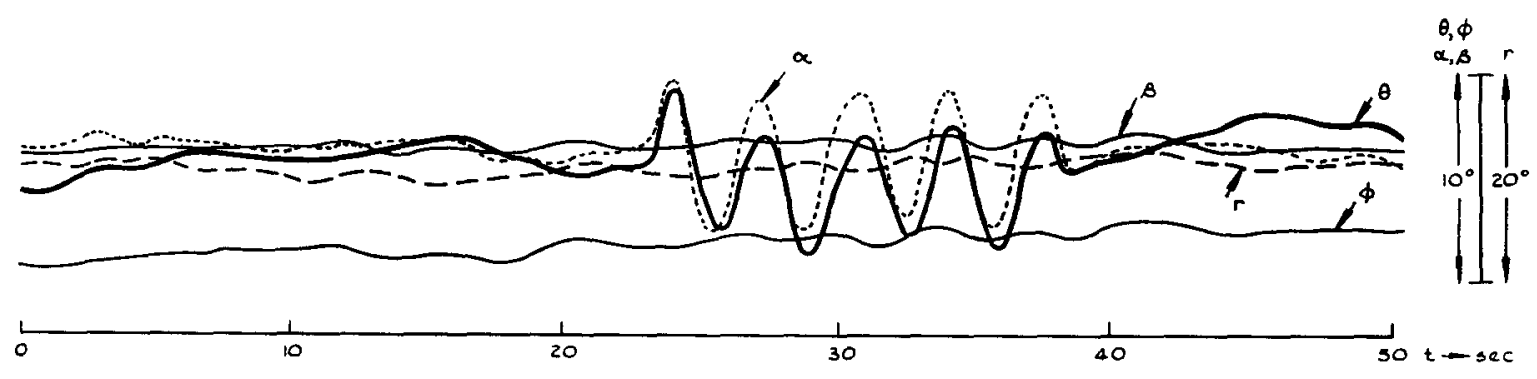

a.

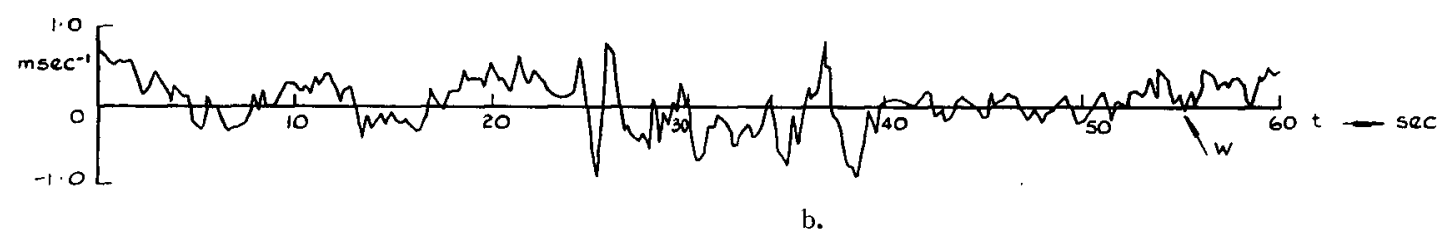

FIG. 3. Recorder traces, a., and derived vertical gusts $w$, b., for short-period pitching test. 


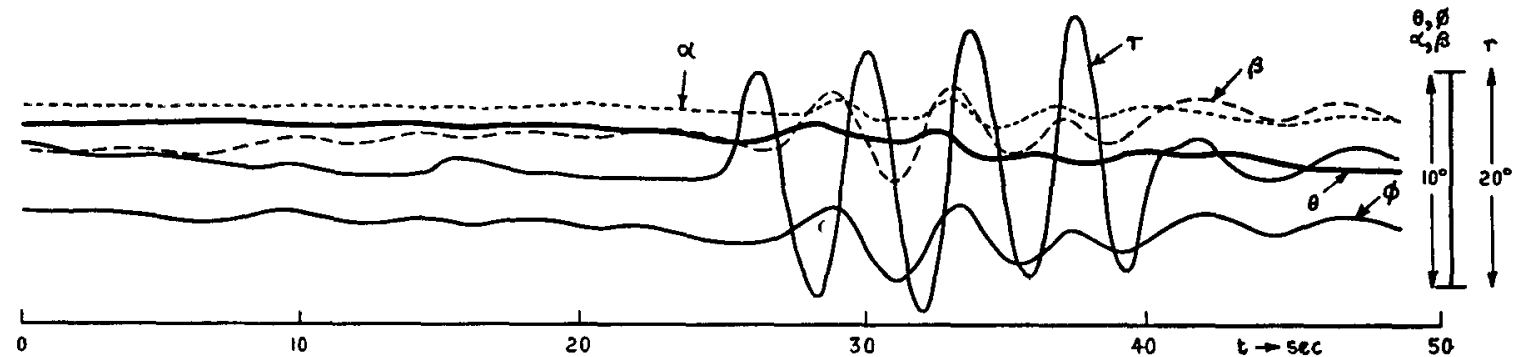

a.

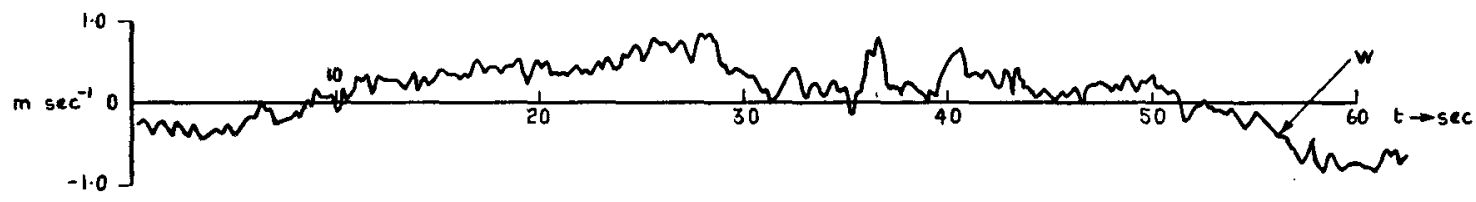

b.

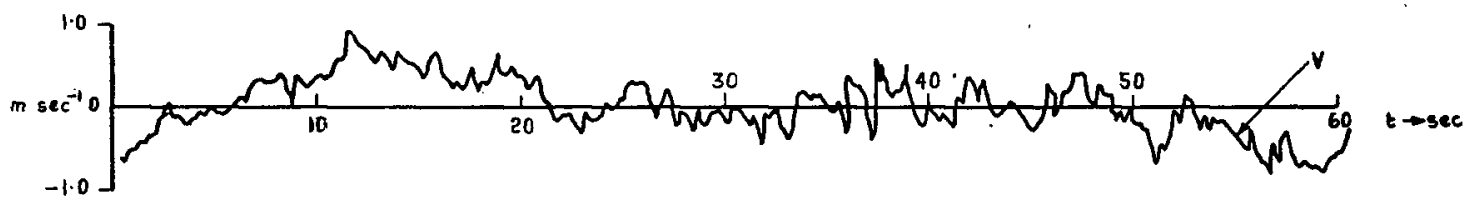

c.

Fig. 4. Recorder traces, a., and derived vertical gusts $w$, b., and lateral gusts $v$, c., for short-period rolling test.

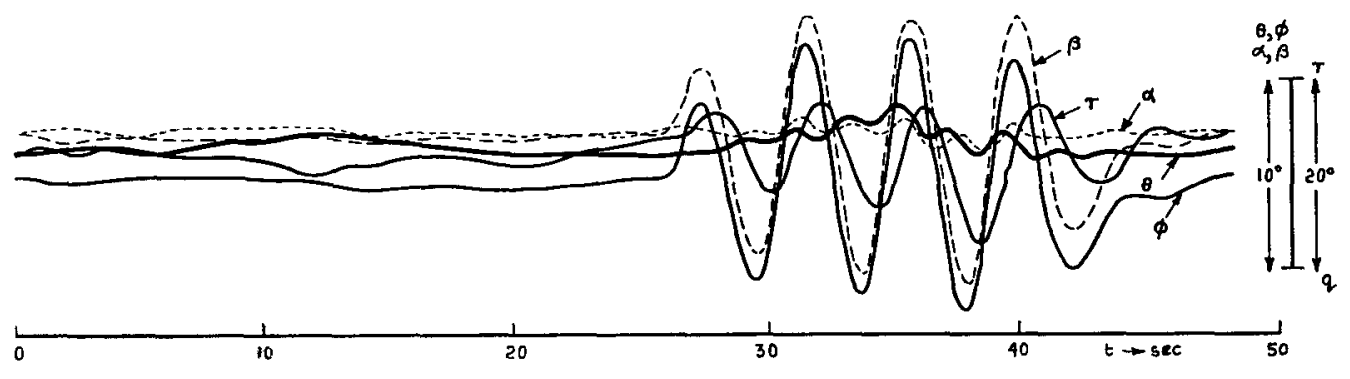

a.

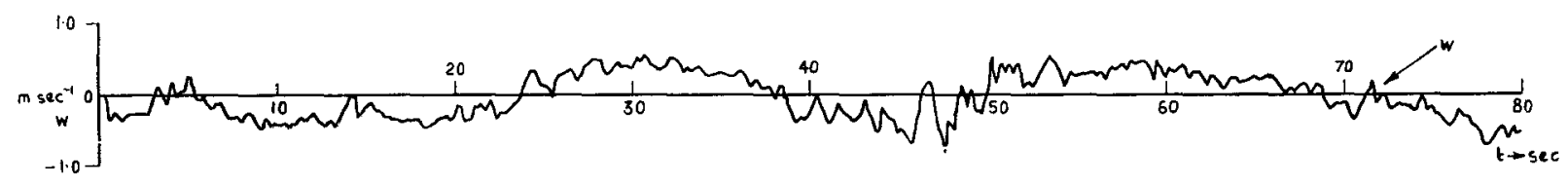

b.

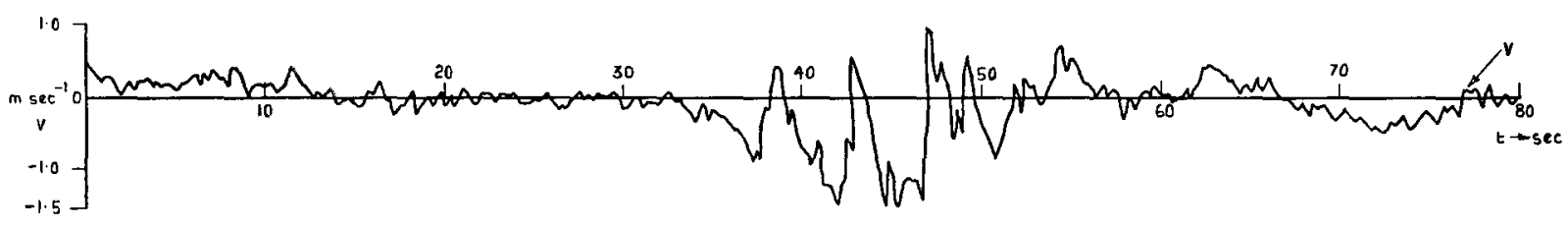

c.

Fig. 5. Same as Fig. 4 except for short-period yawing test. Time scale in a. should start with $t=10$ sec rather than $t=0$. 
In most cases of horizontal shear found in flight the aircraft will not sideslip to any great extent, and thus the error will normally be within $\pm 1 \mathrm{~m} \mathrm{sec}^{-1}$.

e. Long-period yaw test. Fig. 6a shows the record of a long-period yaw from heading $H$, to $(H-8)^{\circ}$ to $(H+8)^{\circ}$ and back onto heading over 40 sec. There were no significant vertical motions. The horizontal lateral gust trace derived from this record is shown in Fig. 6b. There is an initial disturbance during the first $15 \mathrm{sec}$ of range $\pm 1.2 \mathrm{~m} \mathrm{sec}^{-1}$ after which the equations balance to within $\pm 1 \mathrm{~m} \mathrm{sec}^{-1}$.

f. Straight and level fight, downwind in smooth air. As a final check a downwind run was made in clear, smooth air, and a 2-min period (equivalent to $15 \mathrm{mi}$ of flight) was analyzed. The results, in Figs. $7 \mathrm{a}$ and $7 \mathrm{~b}$, show that $w$ and $v$ both lie within $\pm 1 \mathrm{~m} \mathrm{sec}^{-1}$.

This test was made downwind because it has been found that, even in a broad, smooth, synoptically constant airflow, there are significant mesoscale variations in wind velocity across the flow over distances of $10-15 \mathrm{mi}$.

The high-frequency fluctuations shown on this trace are attributable to errors in the manual transfer of the data from the photographic traces to punched tape. They are, therefore, a measure of the "noise" caused by the human in the analyzing process, since in this case all the variables in the gust equations were varying smoothly.

g. Conclusions from the simulation tests. The aircraft motions described in Sections $4 \mathrm{a}-4 \mathrm{e}$ are as violent as those due to severe turbulence. The maximum vertical velocity change measured in a 0.25 -sec interval was $2.2 \mathrm{~m} \mathrm{sec}^{-1}$, giving a rate of change of vertical velocity of almost $9 \mathrm{~m} \mathrm{sec}-2$. It may therefore be concluded that under conditions of smaller aircraft motion a target accuracy of $\pm 1 \mathrm{~m} \mathrm{sec}^{-1}$ can be achieved, and that calculated gust velocities greater than this may be attributed to real vertical gusts and real horizontal shears.

Further, tests such as these may be used to check the stability of the various sensitivities and calibration factors used in the equations. Residual velocities in smooth air in excess of $1 \mathrm{~m} \mathrm{sec}-1$ are shown to be excessive, and if they occur, they indicate a change, or an error, in one or more of the sensitivity factors.

The long-period accuracy of the calculated gust velocities depends on a correct estimate of the gyrodrift correction. However, for short periods of time, or sharp-edged gusts, gyro-drift is not a relevant factor. Measurements of rapid fluctuations in clear air turbulence, or local updrafts in cumulus which show variations of more than $1 \mathrm{~m} \mathrm{sec}^{-1}$ are thus shown to be real and accurately measured to $\pm 1 \mathrm{~m} \mathrm{sec}^{-1}$ by the system now employed in the M. R. F. aircraft.

\section{A measurement of the vertical mesostructure of the atmosphere above and below the tropopause}

The routine rawinsonde ascents which are made twice daily from standard radiosonde stations give measurements of the wind and temperature structure in the vertical which are normally used in synoptic analysis. While these measurements are valid on a large scale, they are smoothed values over depths of several hundreds of meters.

Reiter (1961), Briggs and Roach (1963), and others have reported on aircraft observations in the neighborhood of jet streams, but again the detail of the vertical

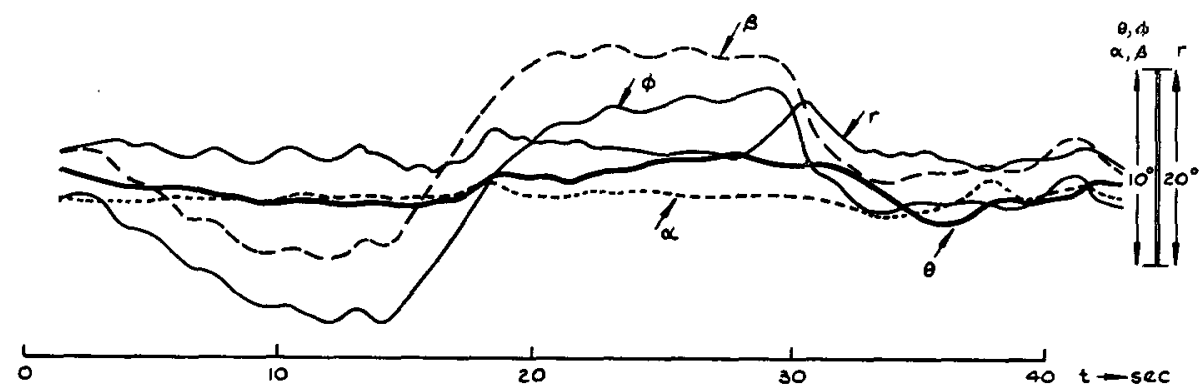

a.

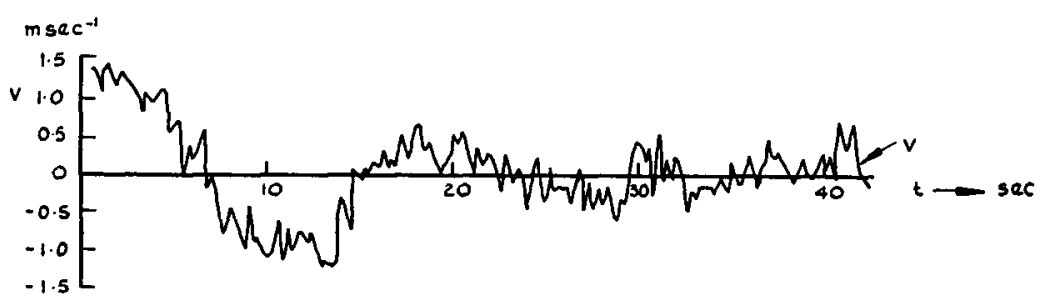

b.

FIG. 6. Recorder traces, a., and derived lateral gusts $v$, b., for long-period yawing test. 


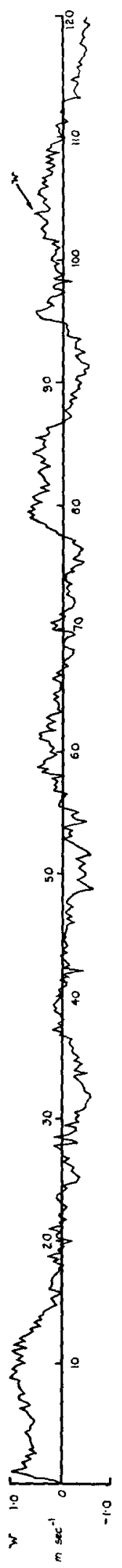

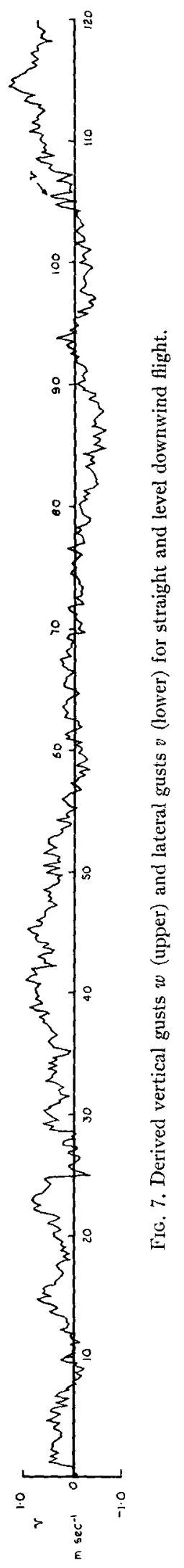

structure has had to be smoothed owing to the large time differences between successive horizontal traverses across each given height.

Sawyer (1961) considered the possibility of inertial waves existing within discrete layers in the stable stratification of the lower stratosphere, with reference to some radiosonde wind profiles over Crawley, England, and further evidence for these perturbations has been produced from balloon measurements by Reiter (1963), Angell (1967), Barbé et al. (1967), and others. In particular, Weinstein et al. (1966), in studying a series of wind observations obtained from spherical superpressure balloons, conclude that a stably stratified, layered mesostructure exists consisting of thin horizontal layers which move relative to each other without appreciable interchange, and within which persistent pseudo-inertial oscillations occur.

The flight plan described in this section was devised in order to investigate the presence of thin shear layers near the tropopause and to determine any correlation between these and the temperature structure. This flight was one of the first of a series of such flights, which have only become possible with the use of an inertial platform.

a. Flight plan for measuring vertical shear profiles. The flight pattern chosen for an experiment is governed by the experimental objective, a number of considerations concerned with the aircraft performance, and the effort involved in processing the raw data. In this case the objective was to obtain measurements of the vertical temperature, wind and turbulence structure from the lower stratosphere through the tropopause in the neighborhood of a jet stream.

Air temperature is measured from the M. R. F. Canberra by a Rosemount platinum resistance thermometer, Model 102E, which has a time constant of approximately $0.02 \mathrm{sec}$. Corrections are made in the standard manner to allow for kinetic and self heating. The differential accuracy of these calculated temperatures is better than $0.3 \mathrm{C}$ while the absolute accuracy is about $1 \mathrm{C}$.

Mean wind measurements in straight and level flight are obtained from a Doppler navigation radar. The radar measures ground speed and the drift angle between the aircraft heading and the ground track direction. By flying reciprocal straight and level runs of $3 \mathrm{~min}$ duration, it is possible to deduce mean winds for the legs which are accurate to within $2.5 \mathrm{~m} \mathrm{sec}^{-1}$ vector error (Murgatroyd and Helliwell, 1959).

In order to measure the vertical shear in the horizontal winds for a given time and at a given air position, it is ideally necessary to be at all levels in the vertical column at the same time. One approach to this ideal is to make an aircraft descent at a controlled rate for a period long enough to cover the depth of atmosphere of interest. In the present case a rate of descent of about $900 \mathrm{~m} \mathrm{~min}^{-1}$ for 3 min gives a sample of almost $3 \mathrm{~km}$ vertical extent while the aircraft moves 
horizontally some $30 \mathrm{~km}$. Using the inertial platform as the stable reference during the descent, it is possible to calculate the vertical and horizontal components of the wind shear.

Because of the horizontal movement of the aircraft, interpretation of the measurements is complicated since it is not possible to say whether any significant feature should be attributed to the vertical profile or the horizontal displacement. This difficulty is overcome by immediately ascending to an air position vertically above the end point of the descent, and descending again in the opposite direction to an air position vertically below the start position of the first descent.

The complete flight plan, including Doppler wind measurements at the top and bottom of each run, is shown in Fig. 8. The time taken from the start of the first descent to the end of the second descent is just over 30 min. Thus, the plan may only be used to look at features in the vertical which are approximately constant over a period of $30 \mathrm{~min}$, and are relatively large in the horizontal compared with the base line of $30 \mathrm{~km}$. The vertical resolution is determined by the response time of the instrumentation, the rate of descent, and the time interval between analyzed measurements. With the present equipment, data is extracted from a photographic trace by hand, and an interval of $0.25 \mathrm{sec}$ is suitable. For a descent rate of $900 \mathrm{~m} \mathrm{~min}{ }^{-1}$, this gives a reading at approximately every $4 \mathrm{~m}$ in the vertical.

b. The flight of 15 March 1967. On 15 March 1967 the flight objective was to measure the vertical profile between 12.3 and $9.3 \mathrm{~km}$ in the neighborhood of the jet known to be lying just north of Aughton. Aircraft endurance restrictions limited the northward extent of the flight to $53 \mathrm{~N}$. The flight profile shown in Fig. 8 was flown initially at right angles to the wind direction and then up- and downwind. The navigational points for the start and finish of each descent were determined relative to air positions; that is to say, the flight profile was followed with respect to the mean air flow and not to the ground surface below.

In Fig. 9 the full arrowed lines show the time and ground positions during each descent as the aircraft drifted downwind, while the dotted arrows show the air positions relative to the start point of the first descent.

c. Synoptic situation of 15 March 1967. A deep low over southeast Iceland at midday on 14 March moved steadily northeast, and an associated cold front moved southeast across the British Isles during the night of 14-15 March. By midday on 15 March it lay from the Isle of Wight to the south of London and it continued to move into the continent during the next $6 \mathrm{hr}$.

In the upper air flow a shallow trough to the rear of the cold front moved rapidly east so that at $300 \mathrm{mb}$ the maximum winds at Aughton veered from $240^{\circ}, 50$ $\mathrm{m} \mathrm{sec}^{-1}$, at $0600 \mathrm{GMT}$ to $280^{\circ}, 50 \mathrm{~m} \mathrm{sec}^{-1}$, by 1200 GMT. This veer in the upper flow was associated with the movement of a cold anticyclone which was moving east into the Southwest Approaches.

The cross section from Camborne to Shanwell for 1200 GMT (Fig. 10) shows the broad synoptic features. The jet core of just over $50 \mathrm{~m} \mathrm{sec}^{-1}$ was centered north of Aughton with the main tropopause gap further north still. The U. K. rawinsonde ascents indicated that the jet maximum rose from $340 \mathrm{mb}$ near Long Kesh to $260 \mathrm{mb}$ near Hemsby and the tropopause rose from $280 \mathrm{mb}$ in the west to $230 \mathrm{mb}$ in the east.

The descents were made on the south or warm side of the jet. The flight report notes that on the climb to

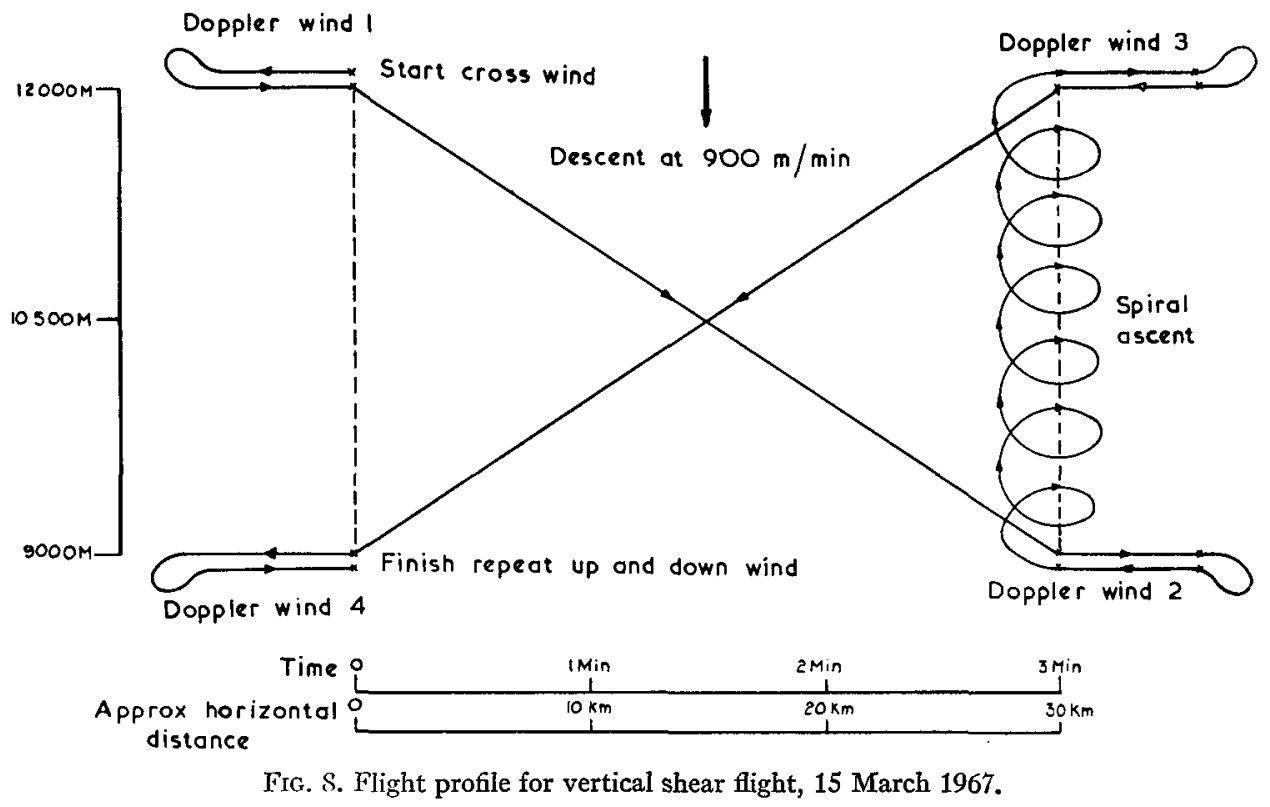




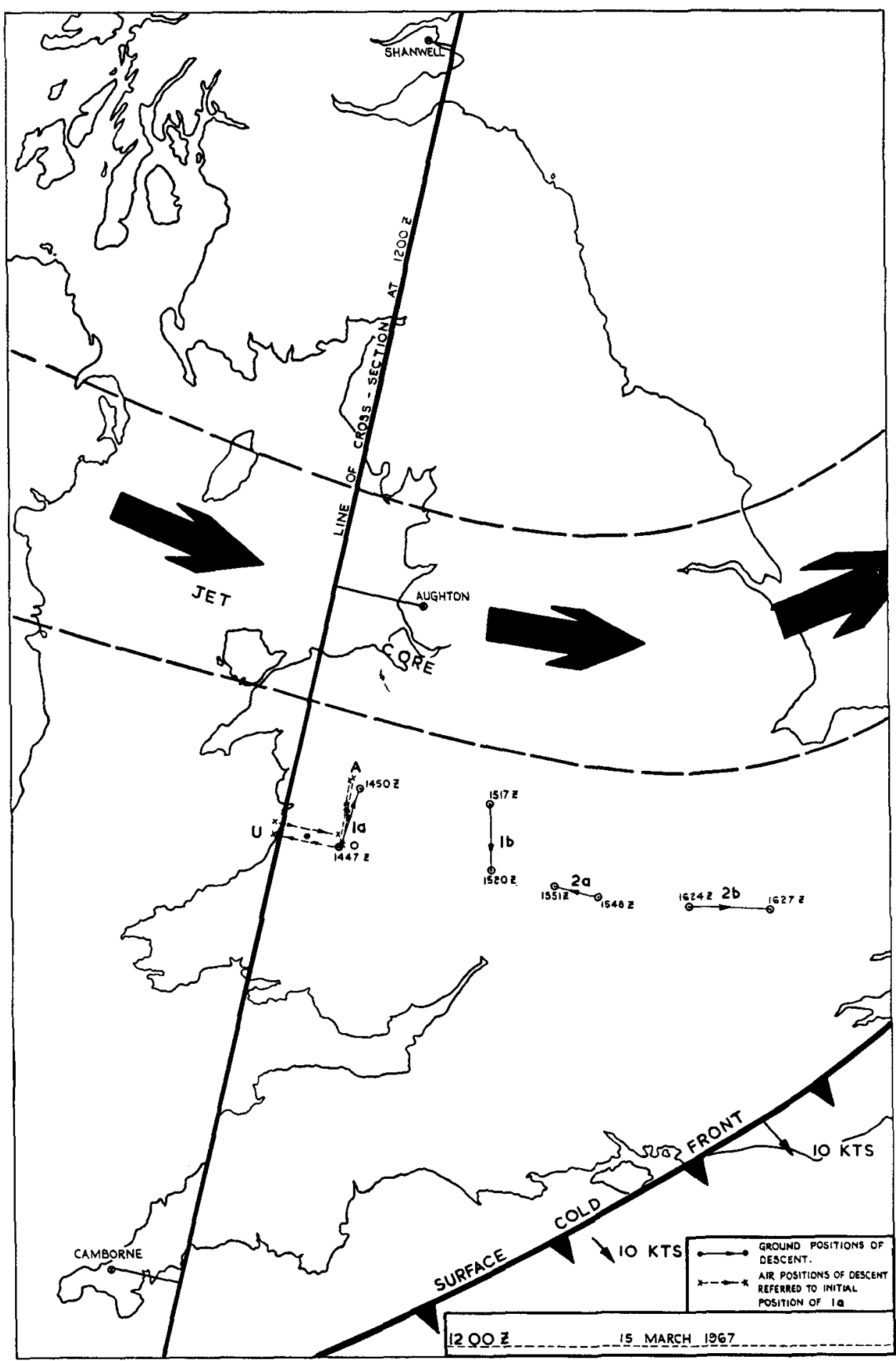

FIG. 9. Position of vertical shear flight, 15 March 1967.

the start point slight to moderate clear air turbulence was found between 9.7 and $10.5 \mathrm{~km}$. During the planned descent flights, slight clear air turbulence (SCAT) was experienced on each occasion. The cloud observed was cirrus between 9.5 and $9.7 \mathrm{~km}$ with $2-3$ eights of small $\mathrm{Cu}$ well below.

\section{d. Analysis of results}

1) Vertical height-time relationship. A major problem in the use of a diving flight plan is caused by incidence errors in the measurement of static pressure, and hence errors in height. Unfortunately, use of the inertial platform in this case is limited, since the effect 


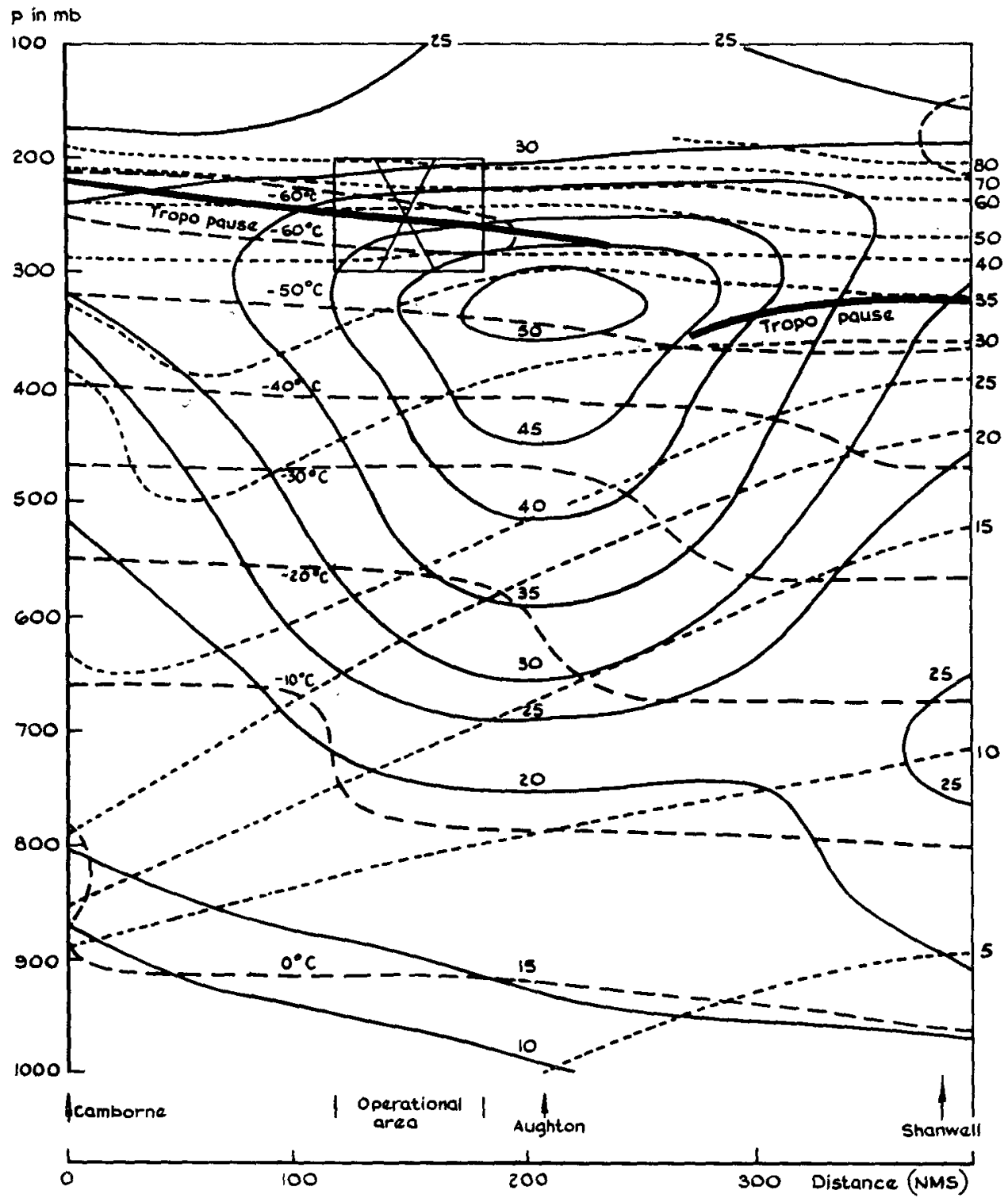

FIg. 10. Cross section from Camborne to Shanwell 1200 GMT 15 March 1967: solid lines, wind speed $\left(\mathrm{m} \mathrm{sec}^{-1}\right)$ perpendicular to cross section; long dashes, temperature $\left({ }^{\circ} \mathrm{C}\right)$; short dashes, potential temperature $\left({ }^{\circ} \mathrm{C}\right)$.

of a double integration of the measured accelerations is to amplify the gyro drift into a large height error. For example, a constant drift rate of $1 \mathrm{~m} \mathrm{sec}^{-1} \mathrm{~min}^{-1}$ for $3 \mathrm{~min}$ implies a height error of $270 \mathrm{~m}$. Thus, while the platform may be used for vertical velocity measurement for periods of up to $5-10 \mathrm{~min}$ without the drift error becoming dominant, for height measurements only very short periods of 10-20 sec are acceptable.

Since the aircraft has a similar pitch attitude in all four descents, the static error will be consistent between one descent and another. Thus, the static height has been related to time in all the measured profiles described in this section. It is realized that these heights may be in error by up to $30 \mathrm{~m}$; however, significant features appearing in more than one descent will appear at the same static height in each profile, and thus be properly related to one another.

2) Temperature profiles. The temperature profiles found in the two cross-wind descents are shown in Fig. 11a. In both cases the tropopause $T$ was at 9.95 $\mathrm{km}$ with a sudden rise in temperature above in a very stable layer about $100 \mathrm{~m}$ thick. On both descents a less stable layer is found between 10.4 and $10.9 \mathrm{~km}$ in which the air temperature falls by $2 \mathrm{C}$. A further stable layer is found above a secondary tropopause ' $T^{\prime}$ continuing up to $11.9 \mathrm{~km}$, with a few small-scale features, in particular a shallow reversed gradient between 11.3 and $11.4 \mathrm{~km}$. There appear to be some significant horizontal temperature differences; for example, the tropopause temperature on the first descent is over $1 \mathrm{C}$ 


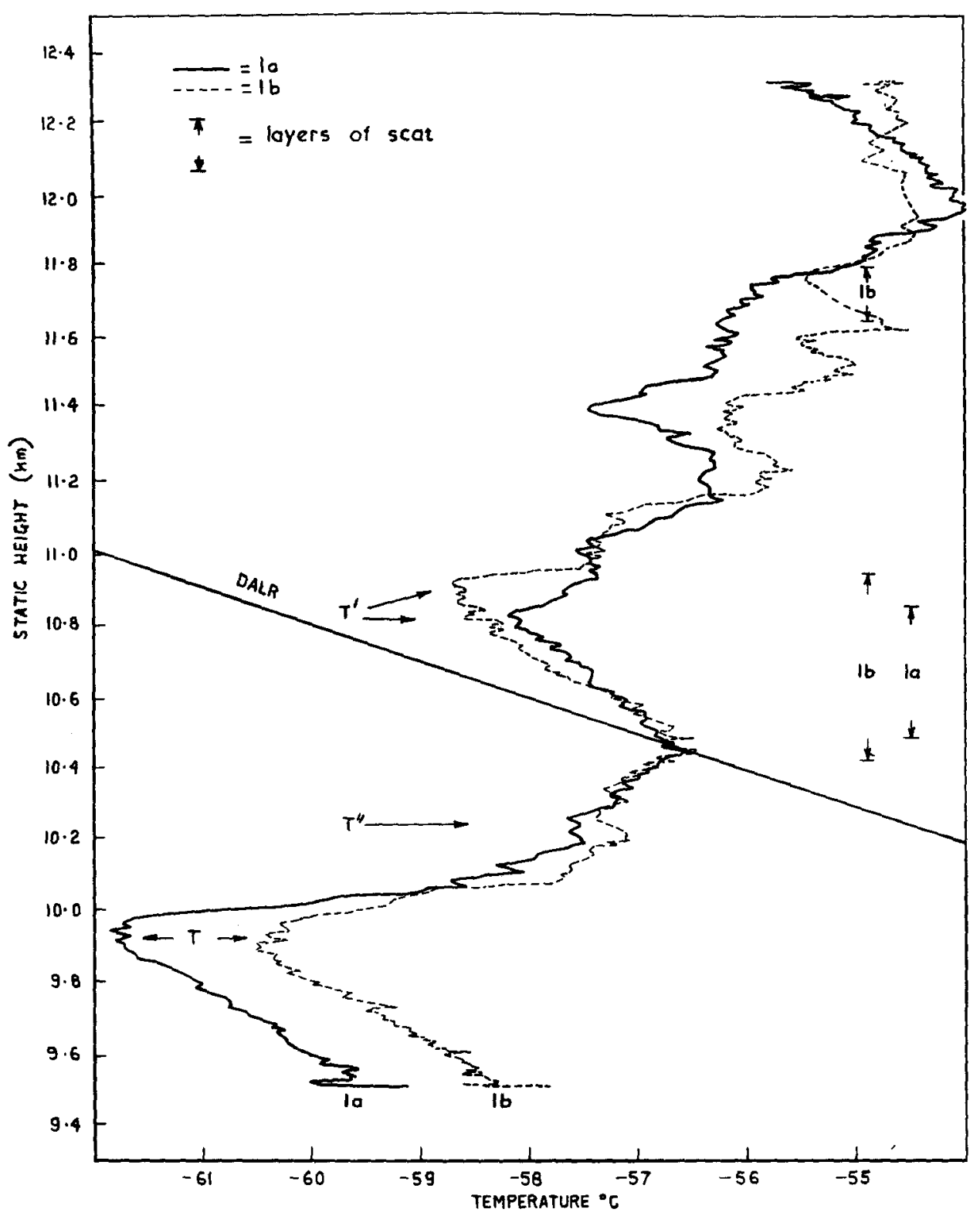

FIG. 11a. Cross-wind temperature vs static height. DALR is the dry adiabatic lapse rate.

colder than on the second descent, but the overall vertical structure is similar in each case.

The two temperature profiles found during the upand downwind descents, Fig. 11b, are almost identical, showing that the isotherms are lying along the airflow on this scale. Again the tropopause $\mathrm{T}$ is at $9.95 \mathrm{~km}$, but in this case the less stable cold layer is from 10.55 to $11.0 \mathrm{~km}$, and again there is a secondary tropopause $T^{\prime}$.

The four temperature profiles have been measured within a 90 -min period, and they may be considered to be positioned with respect to the air positions of the aircraft along $O A$ and $O U$ (Fig. 9). It is then seen that the tropopause $T$ is at a constant height in the two directions $\mathrm{OA}$ and $\mathrm{OU}$ over the 20 -mi distance covered. Above the first tropopause the secondary tropopause is pronounced at $11.0 \mathrm{~km}$ on the center of OU, but less pronounced, $2 \mathrm{C}$ warmer, and $100 \mathrm{~m}$ lower at the center of $O A$ which is at an air position $20 \mathrm{~km}$ further northeast. Thus, the top of this secondary layer appears to be sloping down slightly from southwest to northeast. The lapse rate in the less stable layer below $T^{\prime}$ is just less than the dry adiabatic lapse rate (DALR).

3) Turbulence. As mentioned earlier, slight clear air turbulence of small scale was observed during each descent. Close analysis of the pitch vane, yaw vane, and the pitot-static recordings show variations of pres- 


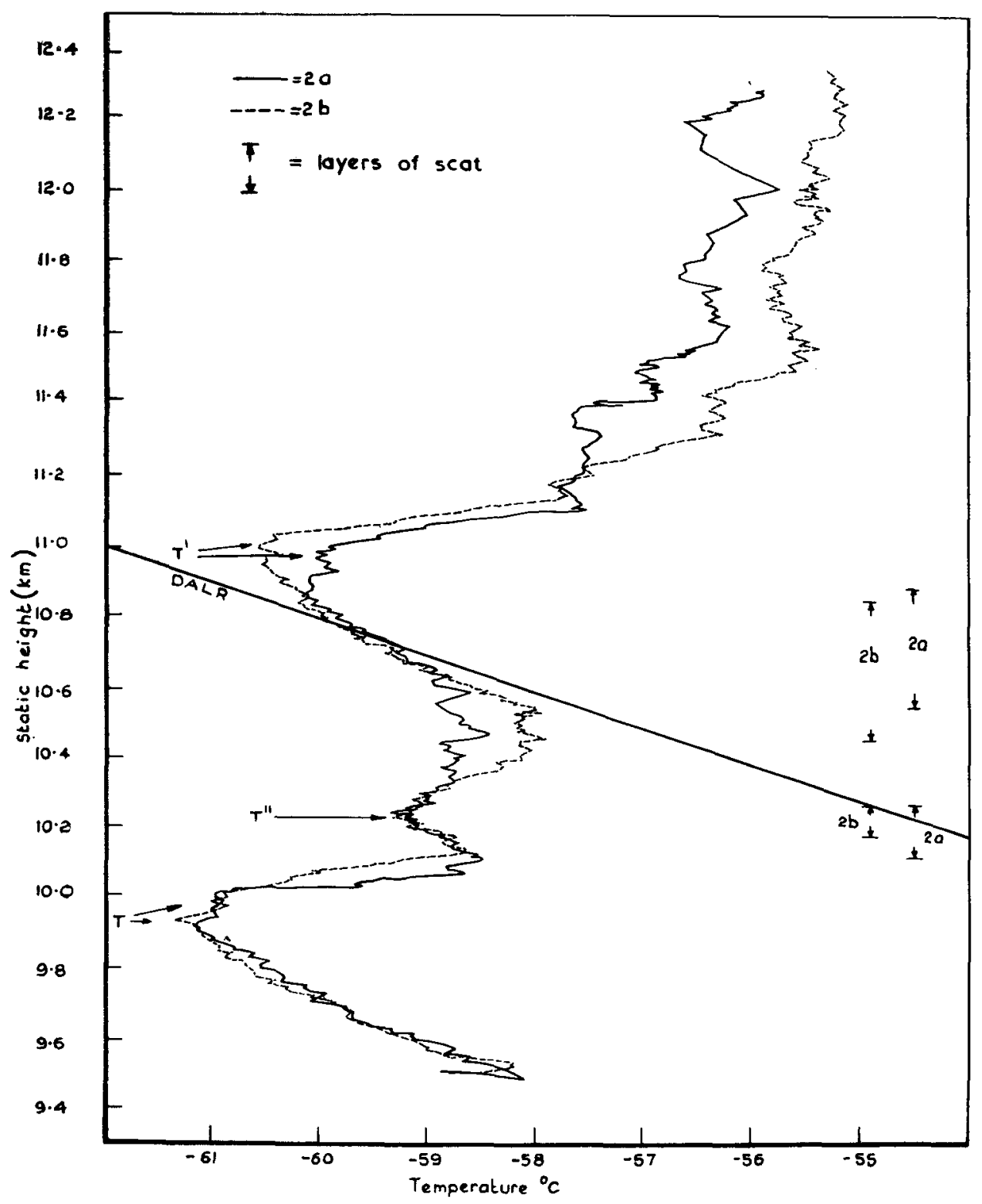

FIG. 11b. Along-wind temperature vs. static height. DALR is the dry adiabatic lapse rate.

sure equivalent to gust speeds of order $1-1.5 \mathrm{~m} \mathrm{sec}^{-1}$ with a period shorter than $0.1 \mathrm{sec}$, i.e., wavelengths of order $20 \mathrm{~m}$. The records clearly show the time of onset of this turbulence and the vertical distributions are shown at the right-hand edge of Figs. 11a and 11b.

In all descents one region of SCAT coincides with the less stable layer associated with the secondary tropopause $T^{\prime}$ above the main tropopause. A secondary short burst of SCAT in the two along-wind cases corresponds with the less stable region of a minor feature $T^{\prime \prime}$ between the two tropopauses $T$ and $T^{\prime}$.

4) Velocity profiles. In using the inertial platform to measure wind velocities over a period of $3 \mathrm{~min}$ it is necessary to have reference velocities at the start and finish of the run so that a correction may be made to allow for the platform drift. For a 3-min period this drift is approximately linear, and, as stated in Section $3 \mathrm{e}$, it will be of order $\pm 1 \mathrm{~m} \mathrm{sec}^{-1} \mathrm{~min}^{-1}$. The Doppler radar winds measured at each end of each descent are used as the horizontal reference velocities, the static pressure measurement in straight and level flight is the vertical reference, and from these the total drift corrections may be calculated.

Table 2 shows the Doppler winds found at the top and bottom of each descent. These winds are consistent, the increase in wind at $9.5 \mathrm{~km}$ at $\mathrm{U}$ over the corresponding wind at $\mathrm{O}$ being due to the presence of the jet stream to the north (Fig. 9). 
TABLE 2. Doppler winds at 12.3 and $9.5 \mathrm{~km}\left(\mathrm{deg} / \mathrm{m} \mathrm{sec}^{-1}\right)$.

\begin{tabular}{|c|c|c|c|c|}
\hline \multirow{2}{*}{ Height } & \multicolumn{2}{|c|}{ Across wind } & \multicolumn{2}{|c|}{ Up- and downwind } \\
\hline & & $1 \mathrm{~b}$ & $2 \mathrm{a}$ & $2 b$ \\
\hline $\begin{array}{r}12.3 \mathrm{~km} \\
9.5 \mathrm{~km}\end{array}$ & $\begin{array}{l}273 / 32 \\
285 / 47\end{array}$ & $\begin{array}{l}270 / 32.5 \\
284 / 42\end{array}$ & $\begin{array}{l}279 / 34.5 \\
284 / 44\end{array}$ & $\begin{array}{l}278 / 35 \\
284 / 43\end{array}$ \\
\hline
\end{tabular}

Figs. $12 \mathrm{a}$ and $12 \mathrm{~b}$ show the velocity profiles found on the descents across the mean wind flow, where $v$, being transverse to the aircraft direction, is therefore along the wind flow, and $u$, being along the aircraft, is across the flow. As explained in Section 3 the lateral gust velocity $v$ is measured to an accuracy of \pm 1 $\mathrm{m} \mathrm{sec}-1$, whereas the longitudinal velocity $u$ has an accuracy of about $\pm 2.5 \mathrm{~m} \mathrm{sec}^{-1}$.
Figs. $12 \mathrm{c}$ and $12 \mathrm{~d}$ show similar profiles found on the up- and downwind descents. Since the aircraft was flying at right angles to the cross wind flight, $v$ is a measurement across the mean flow and $u$ is along the mean flow in these descents.

In these profiles $u$ has been smoothed considerably since a smoothed measurement of airspeed is the best available. The micro-structure in the $v$ profiles has not been smoothed. It appears that most of the small irregularities are random, but that as the wavelength of interest is increased the mesostructure at wavelengths $>100 \mathrm{~m}$ appears to be similar on both profiles. Thus, despite the increased flow in the north at 9.5 $\mathrm{km}$ shown in the $v$ profile of descent 1a, Fig. 12a, the essential details of both descents $1 \mathrm{a}$ and $1 \mathrm{~b}$ are the same from 9.5 to $12.3 \mathrm{~km}$.

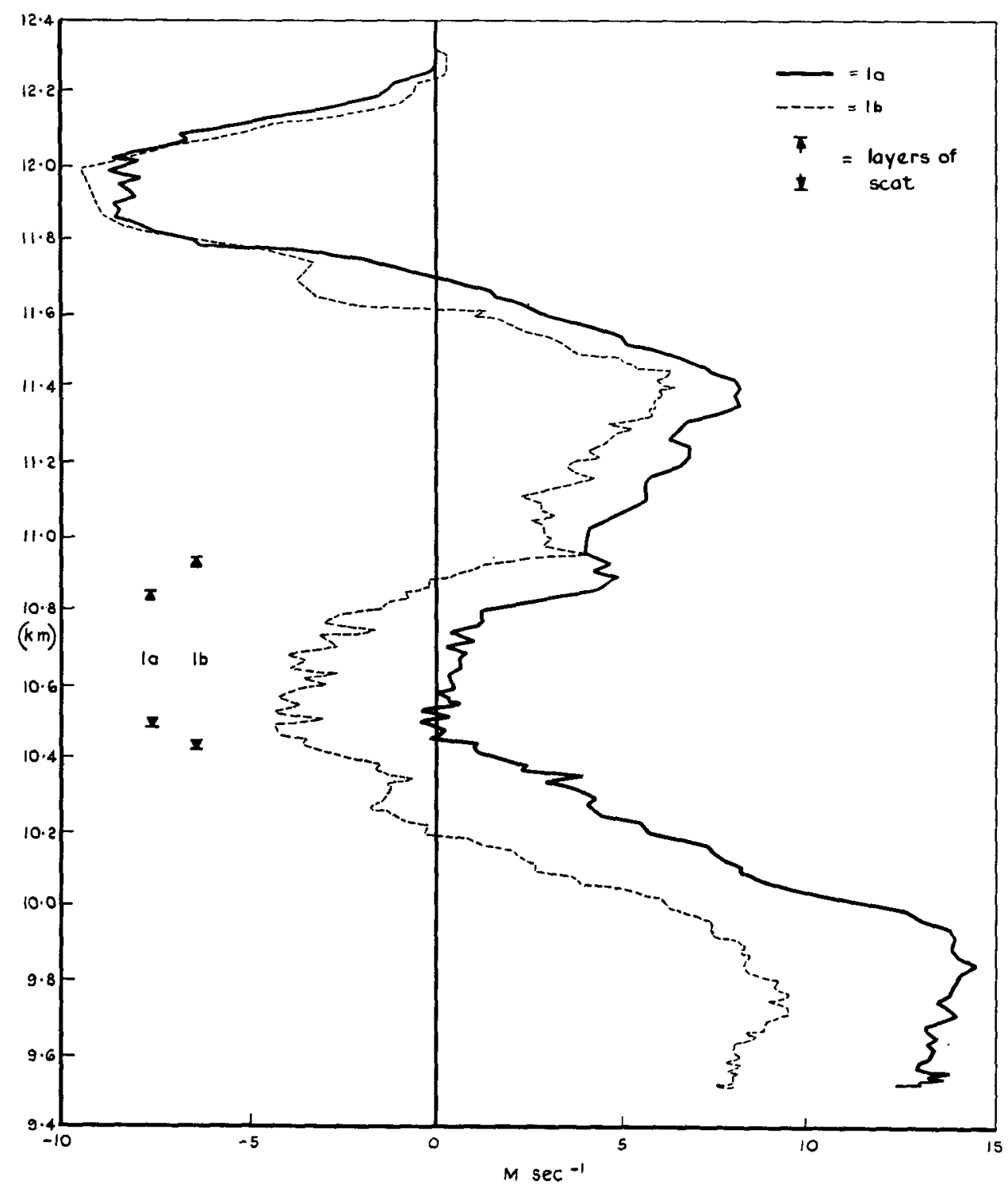

FIG. 12a. Cross-wind velocity $v$ vs static height, where the differential wind component is along $100^{\circ}$. 


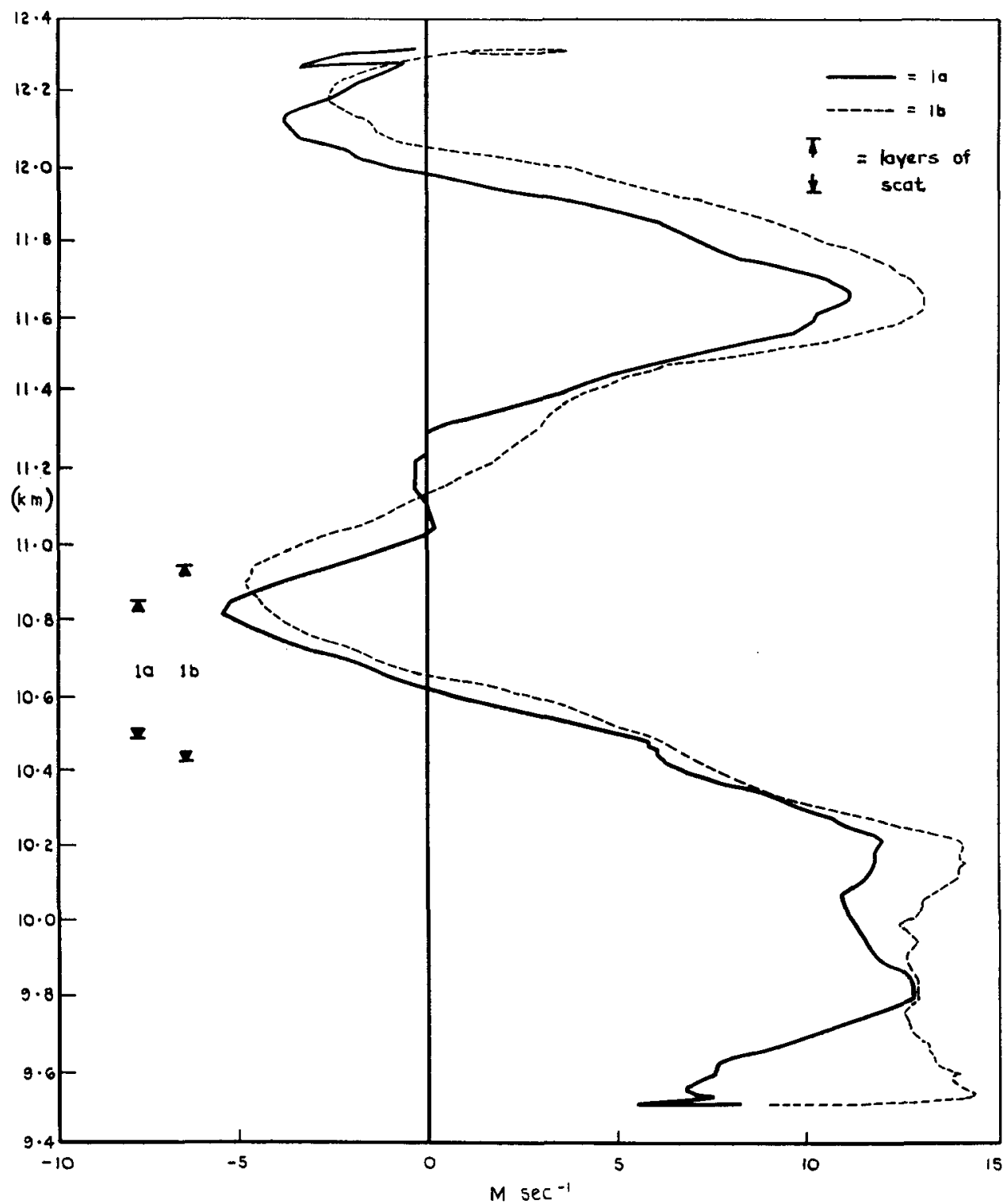

FIG. 12b. Cross-wind velocity $u$ vs static height, where the differential wind component is along $190^{\circ}$.

An interesting small-scale feature between 10.1 and $10.4 \mathrm{~km}$ is barely noticeable in the first two descents, but becomes a major feature in the two along-wind profiles (Fig. 12c). Unfortunately, this is smoothed out in the $u$ profiles, but careful analysis shows that a small perturbation is present at these levels. This feature corresponds well with the short burst of SCAT and less stable region between the tropopause $T$ and $\mathrm{T}^{\prime}$ shown as $\mathrm{T}^{\prime \prime}$ in Fig. 11b.

The vertical gust velocity profiles during the descents are of no great interest. The $w$ velocities remain primarily within $\pm 1 \mathrm{~m} \mathrm{sec}^{-1}$ throughout the descents, with a slight tendency to be positive within the SCAT layer. A typical $w$ profile is shown in Fig. 13.

5) Discussion of results. The velocity profiles shown in Figs. 12a-d may be discussed with reference to the mean hodographs obtained from the cross- and alongwind pairs of descents. The ends of the hodograph vectors in Fig. 14 describe closed loops in a similar direction to those described by Sawyer (1961). The wind variations are persistent in time, at least over the period of $1 \frac{1}{2} \mathrm{hr}$ of this flight, and large shears occur through layers of about $500 \mathrm{~m}$ thickness. The rotation of the hodograph vector suggests that the fluctuations across and along wind are out of phase.

The aircraft drifted with the wind, so the measurements are unlikely to be affected by lee waves from the Welsh Mountains. By maintaining air rather than ground positions during the flight, the measurements attempt to measure the evolution of the mesostructure in a pseudo-Lagrangian sense, and thus are different from a succession of balloon measurements from a 


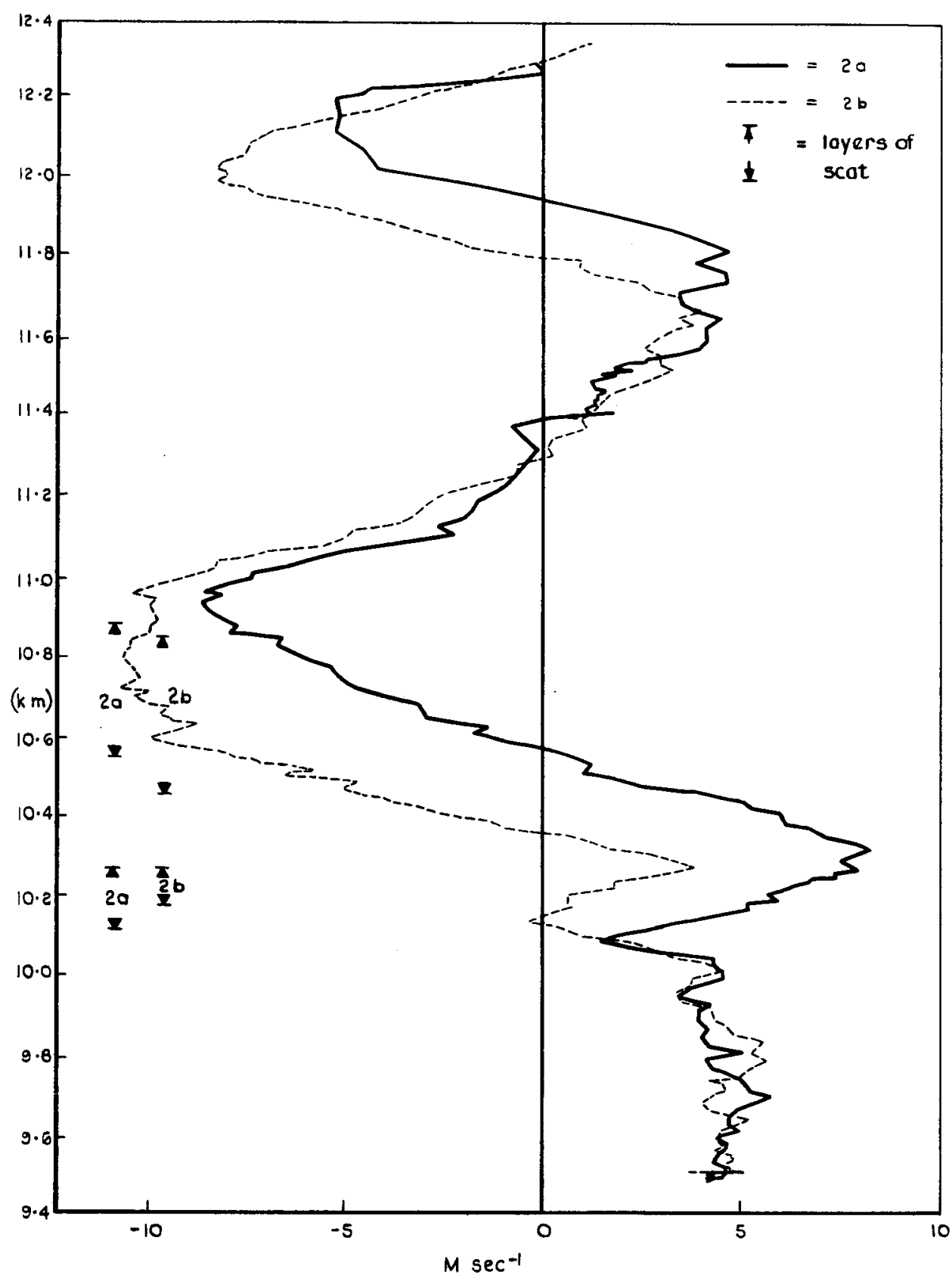

FIG. 12c. Along-wind velocity v vs static height, where the differential wind component is along $190^{\circ}$.

fixed ground position for which advection changes are usually dominant. However, even with a drifting aircraft, advection effects must occur due to the velocity shears occurring between the top and bottom of the layer.

Comparing the hodographs with the temperature profiles, it is found that in the region of low stability and SCAT from 10.4 to $10.8 \mathrm{~km}$, the wind is approximately constant in magnitude but backing rapidly with height. Above this region the wind increases slightly as it veers up to $11.6 \mathrm{~km}$, and then backs again up to $12.1 \mathrm{~km}$.
Turbulence in the bottom shear layer has produced a near adiabatic lapse rate and a secondary tropopause $T^{\prime}$. In a stable stratification the heat flow due to turbulence is downwards (Prandtl, 1952), and thus this secondary tropopause is self-maintaining as long as the shearing stresses maintain the turbulence. This may perhaps account for the lowering of temperature found in this secondary tropopause during the flight.

It is interesting to note that the small feature $T^{\prime \prime}$ at $10.2 \mathrm{~km}$ which appears in Fig. 11b with SCAT is also characterized by the wind backing between 10.0 


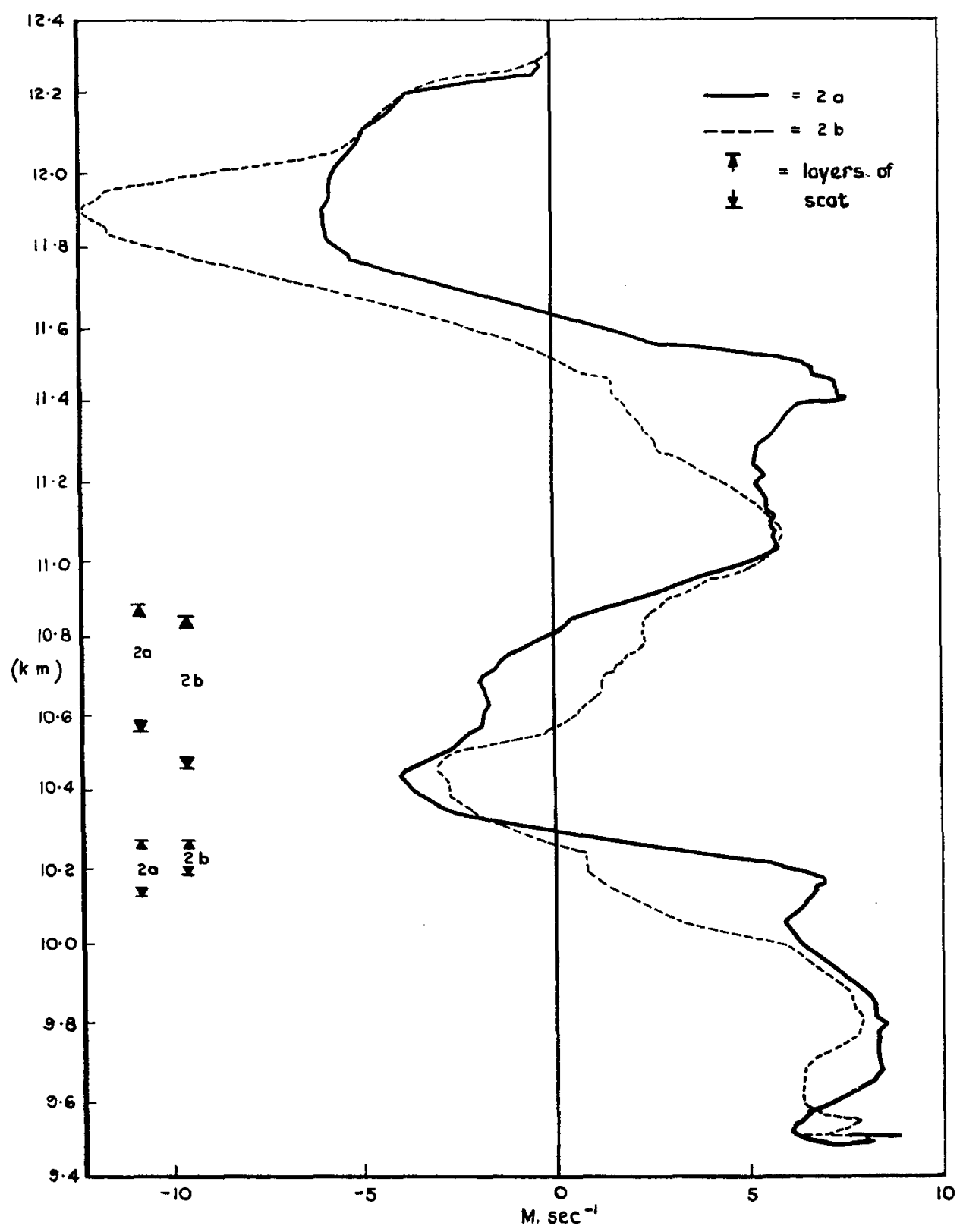

FIG. 12d. Along-wind velocity $u$ vs static height, where the differential wind component is along $100^{\circ}$.

and $10.1 \mathrm{~km}$. The temperature disturbance also shows signs of growing more marked with time.

In conclusion, these aircraft measurements confirm the previous balloon measurements showing that a layered stratification exists above the tropopause with apparent quasi-inertial waves forming in the layers. A correlation is evident between the temperature structure, wind structure and observed SCAT. The SCAT layer is found in a region of low stability and is also associated with a wind which is backing with height. The depth of the layer appears, in this case, to be increasing with time, and the low stability region becomes more pronounced, taking on the character of a second tropopause by the end of the flight.

\section{Conclusions}

The purpose of this paper has been to show the uses and limitations of an inertial platform as currently applied to meteorological research. Without doubt, it is an essential part of the equipment required for making measurements of the atmospheric mesostructure from an aircraft. With it one may measure with considerable accuracy both horizontal and vertical 

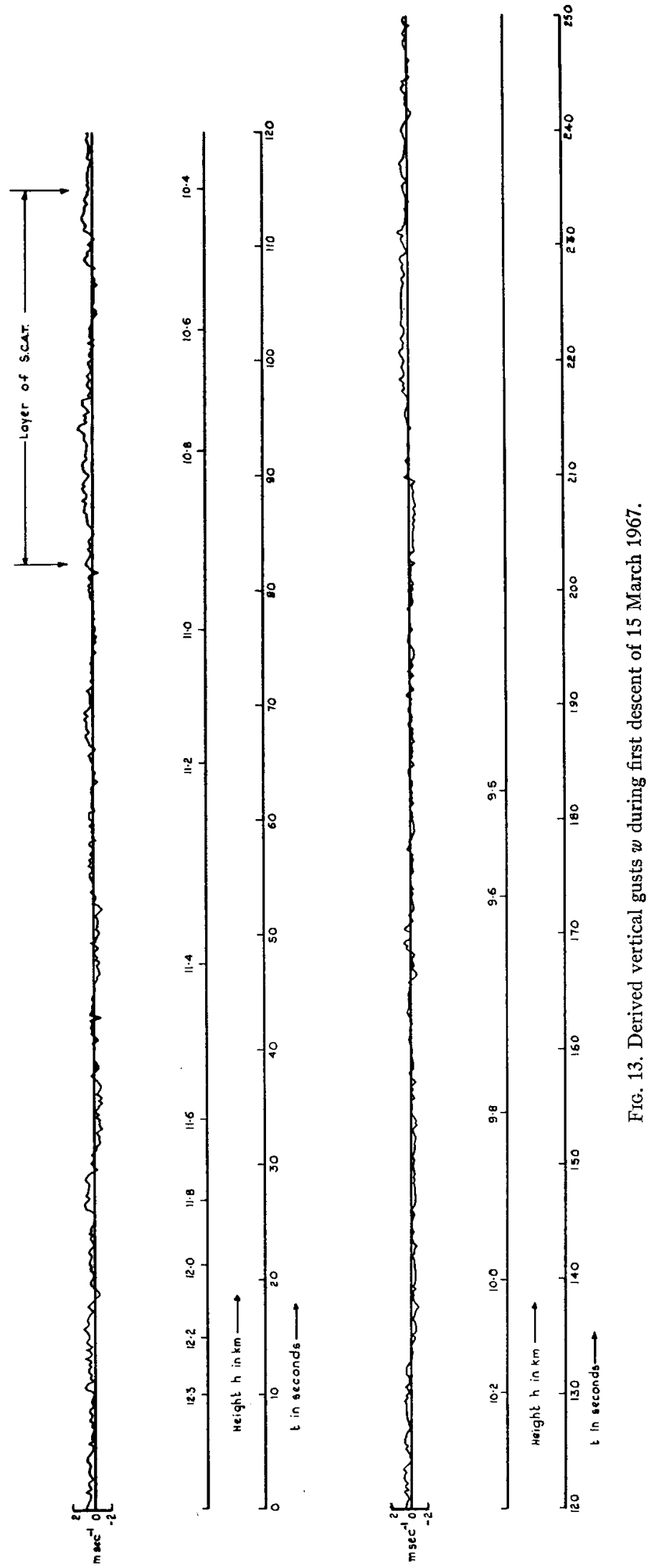

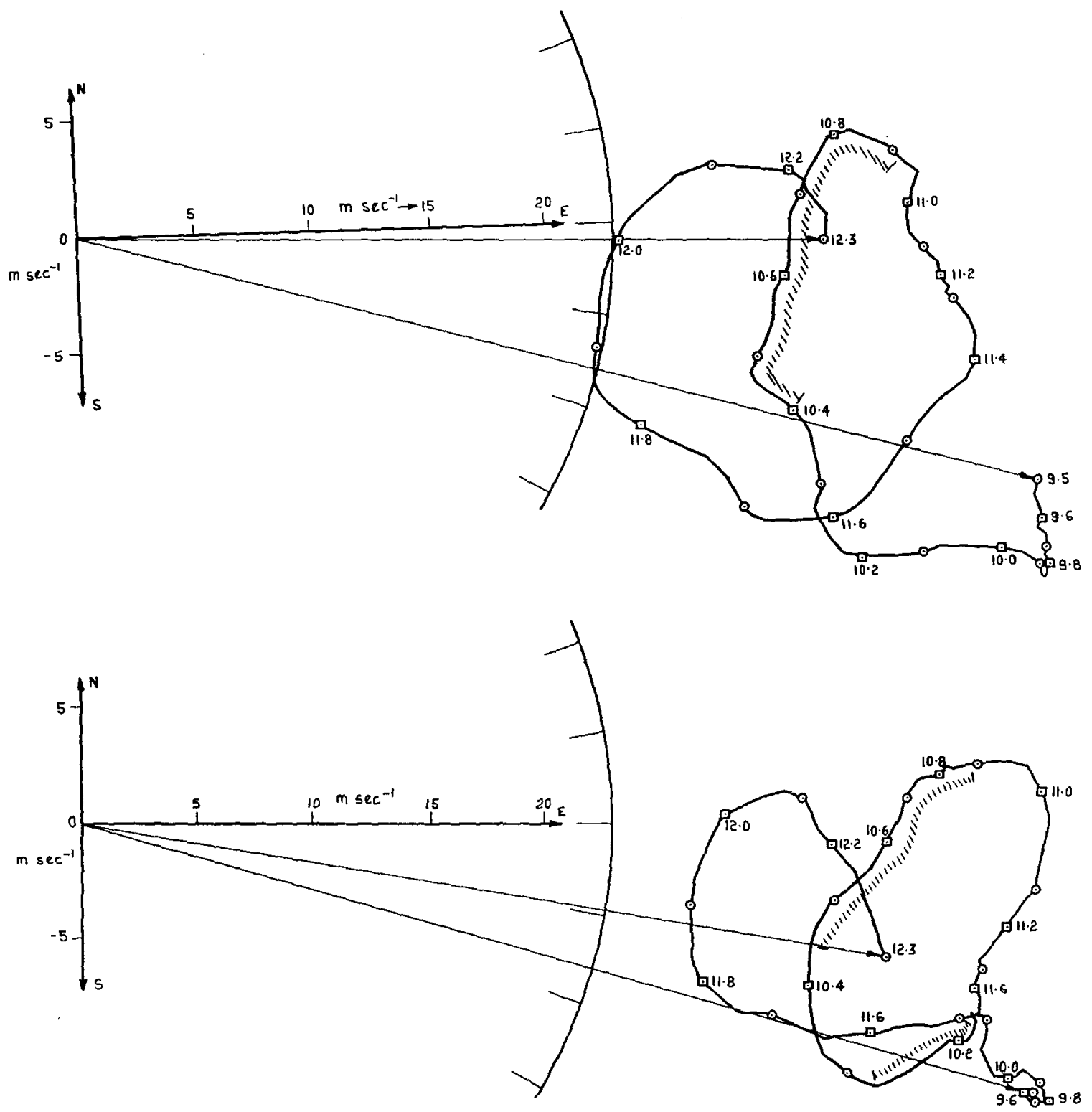

Fig. 14. Hodographs for mean cross-wind descents (upper), and for mean along-wind descents (lower), of 15 March 1967. Observations at even heights in $\mathrm{km}$ are shown by squares, odd heights, circles; hatched areas indicate where SCAT was found.

wind changes, and these may be related to simultaneous measurements of other parameters such as temperature and turbulence.

Instrumentation of this type will find a use in the following fields:

1) Short- and long-wave turbulence measurements in clear air and in cloud.

2) Measurements of vertical up- and downdrafts over horizontal distances of up to 1-2 km, as found in convective clouds.

3) Measurements of lee waves of up to $20 \mathrm{~km}$ wavelength. Here both vertical and horizontal wind velocities are of great interest.
4) Wind shear measurements by vertical soundings as described in Section $\mathbf{5}$.

5) Meso-variations in the horizontal wind along straight and level soundings within the synoptic-scale variations.

Acknowledgments. This paper is published with the permission of the Director-General of the Meteorological Office. I am also indebted to Mr. P. R. Cockrell who helped in developing the data reduction programs, to Mr. D. M. Pusey and Mr. B. R. Kerley who flew as meteorological observers and prepared the data for analysis, and to the R. A. F. aircrew for their help with the flights. 


\section{REFERENCES}

Angell, J. K., 1967: Some evidence of inertial oscillations along transosonde trajectories. Quart. J. Roy. Meteor. Soc., 93, 105-108.

Barbé, G. D., P. Dumas, J. Heisset and M. Passelergue, 1967: Etude expérimentale des gradients de vent et de température a échelle fine. Notes de L'Etablissement d'Études et de Recherches Meteorologiques, No 237, Paris, Bureau d'Études de la Haute Atmosphere, $14 \mathrm{pp}$.

Briggs, J., and W. T. Roach, 1963: Aircraft observations near jet streams. Quart. J. Roy. Meteor. Soc., 89, 225-247.

Broxmeyer, C., 1964: Inertial Navigation Systems. New York, McGraw-Hill Book Co., 254 pp.

Murgatroyd, R. J., and N. C. Helliwell, 1959: The measurement of wind from aircraft using a Doppler navigation system. $J$. Inst. Navigation, 12, 84-89.

Prandtl, L., 1952: Essentials of Fluid Dynamics. London, Blackie and Son, Ltd., $452 \mathrm{pp}$.
Reiter, E. R., 1961: Project Jet Stream research flight No. 30, April 1957. Quart. J. Roy. Meteor. Soc., 87, 332-345.

- , 1963: Exploratory study on the physical nature of certain mesostructural details in vertical wind profiles. Atmos. Sci. Dept., Tech. Paper No. 47, Colorado State University, $17 \mathrm{pp}$. Ross, I., 1966: Inertial navigation and gust measurement from Meteorological Research Flight aircraft. Meteor. Magazine., 95, 370-375.

Sawyer, J. S., 1961: Quasi-periodic wind variations with height in the lower stratosphere. Quart. J. Roy. Meteor. Soc., 87, 24-33.

Telford, J. W., and J. Warner, 1962: On the measurement from an aircraft of buoyancy and vertical air velocity in cloud. $J$. Atmos. Sci., 19, 415-423.

Watson, N., 1967: Measurements of turbulence in altocumulus. Quart. J. Roy. Meteor. Soc., 93, 227-236.

Weinsten, A. I., E. R. Reiter and J. R. Scoggins, 1966: Mesoscale structure of $11-20 \mathrm{~km}$ winds. $J$. A ppl. Meteor., 5, 49-57. 